\title{
Transformation of a rolling mill aggregate to a cyber physical production system: from sensor retrofitting to machine learning
}

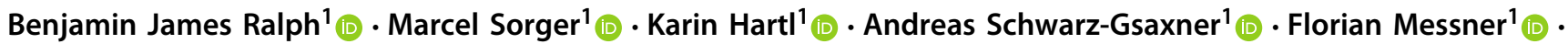 \\ Martin Stockinger ${ }^{1}$ (I)
}

Received: 22 March 2021 / Accepted: 23 September 2021 / Published online: 24 October 2021

(c) The Author(s) 2021

\begin{abstract}
This paper describes the transformation of a rolling mill aggregate from a stand-alone solution to a fully integrated cyber physical production system. Within this process, already existing load cells were substituted and additional inductive and magnetic displacement sensors were applied. After calibration, those were fully integrated into a six-layer digitalization architecture at the Smart Forming Lab at the Chair of Metal Forming (Montanuniversitaet Leoben). Within this framework, two front end human machine interfaces were designed, where the first one serves as a condition monitoring system during the rolling process. The second user interface visualizes the result of a resilient machine learning algorithm, which was designed using Python and is not just able to predict and adapt the resulting rolling schedule of a defined metal sheet, but also to learn from additional rolling mill schedules carried out. This algorithm was created on the basis of a black box approach, using data from more than 1900 milling steps with varying roll gap height, sheet width and friction conditions. As a result, the developed program is able to interpolate and extrapolate between these parameters as well as different initial sheet thicknesses, serving as a digital twin for data-based recommendations on schedule changes between different rolling process steps. Furthermore, via the second user interface, it is possible to visualize the influence of this parameters on the result of the milling process. As the whole layer system runs on an internal server at the university, students and other interested parties are able to access the visualization and can therefore use the environment to deepen their knowledge within the characteristics and influence of the sheet metal rolling process as well as data science and especially fundamentals of machine learning. This algorithm also serves as a basis for further integration of materials science based data for the prediction of the influence of different materials on the rolling result. To do so, the rolled specimens were also analyzed regarding the influence of the plastic strain path on their mechanical properties, including anisotropy and materials' strength.
\end{abstract}

Keywords Cyber physical production system $\cdot$ Retrofitting $\cdot$ Digitalization $\cdot$ Digital twin $\cdot$ Machine learning $\cdot$ Smart Forming Lab $\cdot$ Industry 4.0

\section{Introduction}

The ongoing fourth industrial revolution forces manufacturers around the globe to face significant changes in their possibilities to plan and steer production processes and overlying operations (Zheng et al., 2021; Zhong et al., 2017). Despite all the advantages the connection and network technologies offer (e.g. digital value chain, one-piece flow concept, circular economy), there are crucial thresholds to

Benjamin James Ralph

benjamin.ralph@unileoben.ac.at

1 Chair of Metal Forming, Montanuniversität Leoben, Franz Josef Strasse 18, 8700 Leoben, Austria overcome in order to implement digitalization technologies in a successful and sustainable way (Enyoghasi \& Badurdeen, 2021; Gupta et al., 2021; Reiman et al., 2021). These thresholds can be divided into investment (economic related) and socio-cultural (management and psychology related) challenges. Regarding investment issues, especially SMEs face a serious problem, as most digitalization approaches are highly scalable, making the amortization time for necessary investments much longer for this kind of businesses (Müller et al., 2018). This also includes the required human capital to implement infrastructural changes within a company. To sustain the digital change in the manufacturing environment, responsible managers must be aware of potentials and possible threats on 
the technical as well as working environment layer (Akkaya, 2019).

To contribute to the solution of these issues, this paper focusses on two main objectives:

a. Reducing the investment costs for smaller companies by using mainly open source software (SW) and costeffective but suitablē hardware (HW),

b. Development of a resilient Cyber Physical Production System (CPPS) which can be used to educate engineering students and therefore future production managers as well as other interested parties from the manufacturing industry segment in the topic of digitalization and associated technologies.

In order to create a case study which fulfills the requirements of (a) and (b), an already existing metal forming aggregate at the Smart Forming Lab (SFL) at the Chair of Metal Forming (CMF) of the Montanuniversitaet Leoben was chosen (Ralph et al., 2020). For this purpose, the CMFs rolling mill aggregate was used, as it can serve as an ideal example of how retrofitting from sensor application up to implemented machine learning algorithms can be integrated successfully in a low-cost (LC) resilient digitalization layer architecture (Ralph et al., 2021a, 2021b, 2021c). This brownfield approach is also a common initial state within the metal forming and metallurgical environment, as the production asset life span tends to be significantly higher than in other industry segments (Ball et al., 2020; Elkins et al., 2004). Especially considering SMEs and their lower investment budget, brownfield approaches dominate when it comes to digitalization approaches in comparison to corresponding greenfield investments (Sorensen et al., 2019).

Further considering this financial restrictions, most SMEs face, LC solutions based on open-source software tend to be a suitable option for the implementation of Industry 4.0 related digitalization approaches (Buer et al., 2021; Denicolai et al., 2021; Dutta et al., 2021). Furthermore, as the metal forming industry heavily relies on process models to decrease the quality related costs, this software can support the integration of these models within the manufacturing operations, as most solutions tend to have more suitable interfaces to connect directly with simulation related program environments (Ralph et al., 2021a, 2021b, 2021c; Schwarz et al., 2021). One disadvantage of this approach are the required skill sets to maintain and adapt such open-source solutions, as IT skills remain a scarce resource especially in SMEs operating in the manufacturing environment (Dethine et al., 2020; Eller et al., 2020; Kergroach, 2020).

For this reason, this paper demonstrates a new approach for the transformation of outdated machine systems into CPPS, demonstrated by a rolling mill system initially put into operation in 1954. The novelty within this approach is the focus on suitable low-cost hardware and opensource software wherever applicable, to consider the limited financial capabilities of most SMEs and similar facilities. Furthermore, by taking into account the possible lack of IT-specialists within this environment, the user-friendliness in terms of operating and mainting this kind of CPPS was another special focus of this work. Based on the rolling mill example, this paper describes the most important principles of sheet metal rolling and an SME tailored CPPS approach in (2), followed by the initial setup before the transformation of the respective machine system in (3). Section 4 describes the required and applied sensor technology (4.1) as well as the digitization of the given sensor data (4.2), whereas the sensor selection was based on the principle of low-cost by maintaining sufficent accuracy, connectivity and reliability. In (5), the upfollowing digitalization approach including an appropriate HMI is discussed, based on the same requirements as in (4). Section 6 demonstrates the development, implementation and validation of the machine learning algorithm for the system including an additional GUI for the ML application. In (7), the resulting LC user-friendly CPPS is summarized and discussed, followed by a conclusion and a corresponding outlook in (8).

\section{Fundamentals of the rolling process and CPPS}

Within this chapter, the most important characteristics of the rolling process as well as a common definition of a CPPS are introduced. Based on these definitions, the case study will be elaborated, beginning with the initial state (3), followed by digitization (4) and digitalization (5) and the developed data driven (black box) digital twin setup (6) (Ralph \& Stockinger, 2020).

\section{The rolling process}

According to DIN 8580, rolling belongs to the manufacturing processes of forming under compressive loads and to the group of direct forming processes. During the process, a sheet material is formed through the roll gap between at least two rotating rolls, leading to a reduction in the cross-section of the rolled material. (German Institute for Standardization).

During the rolling process, a force flow occurs through the roll stand as a result of the load applied to the processed material. All parts of the roll stand that are directly or indirectly affected from the force flow, undergo an elastic deformation (Wang et al., 2017). Affected parts are the rolls, roll bearings, load cells, adjusting elements and the roll stand itself. This elastic deformation causes the roll gap to increase, from the 


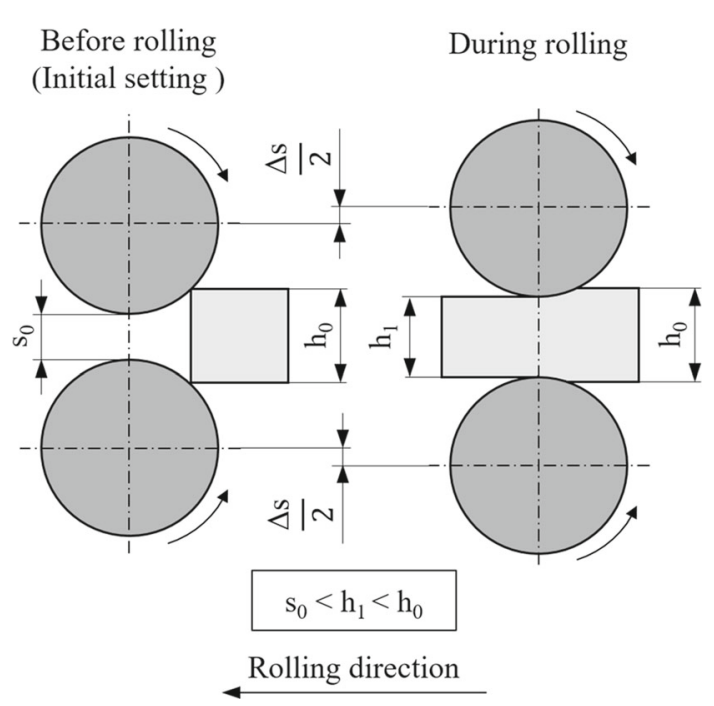

Fig. 1 Geometry change during rolling

initial (set) gap $\mathrm{s}_{0}$ to $\mathrm{s}_{1}$, whereas the difference between is defined as $\Delta$ s (Fig. 1).

$\Delta s=s_{1}-s_{0}$

The end thickness of the rolled sheet $\mathrm{h}_{1}$ can be calculated according to the Gage-meter equation (Lee \& Lee, 1999). The Gage-meter equation specifies the expected exit thickness of the rolled material $h_{1}$ depending on the initial roll gap height $\mathrm{s}_{0}$ and the elastic deformation, which depends on the rolling force $F_{R}$ and the stand modulus $C$. The elastic deformation of the aggregate is characterized by $\mathrm{C}$ and corresponds to the slope of the roll stand module in the rolling gap diagram.

$h_{1}=s_{0}+\frac{F_{R}}{C}$

The rolling gap diagram shows the rolling force $F_{R}$ over $\mathrm{s}_{0}$ and initial material thickness $\mathrm{h}_{0}$ (Fig. 2).

The point of intersection between the roll stand characteristic curve, defined by the slope $\mathrm{C}$, and the materials characteristic curve, defined by the material module in the rolling gap diagram is called the working point (A). A provides information on the exit height of the rolled sheet $h_{1}$ as a function of $F_{R}$ (Fig. 2).

It is important to note that the influence of sheet metal width is not considered as influencing factor of $\mathrm{C}$, but included in the material module. The first hypothesis this paper aims to test can be stated as follows:

- The friction state and resulting rolling force deviations mainly depend on the initial sheet geometry.

Therefore, the contact surface in the roll gap increases the resulting rolling force significantly more than the effect of

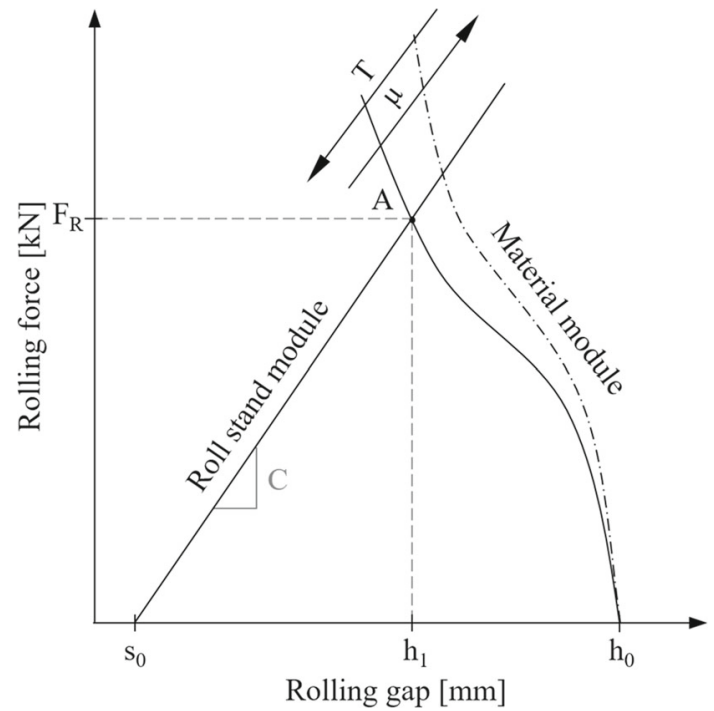

Fig. 2 Work diagram for rolling for a defined $\mathrm{s}_{0}$

a rougher surface topology. In addition, the approximated linear behavior of $\mathrm{C}$ is given for one $\mathrm{s}_{0}$.

The second hypothesis tested within this work and to be elaborate more deeply in Sect. 6 is defined as follows:

- The stand modulus $\mathrm{C}$ behaves non-linear as a function of varying $\mathrm{s}_{0}$ and the overall difference between $\mathrm{h}_{0}$ and $\mathrm{h}_{1}$, $\Delta \mathrm{h}$.

Similar to hypothesis 1, an influence on the material behavior (e.g. due to work hardening) can be observed, although the authors state that the force flow through the machine system also contributes significantly to the change in $\mathrm{h}_{1}$, which as a consequence results in a dependency of $\mathrm{C}$ on $\Delta \mathrm{h}$.

$\Delta h=h_{0}-h_{1}$

\section{Cyber physical production systems (CPPS)}

CPPS can be defined as a derivative from Cyber Physical Systems (CPS), especially tailored to the production segment. Although CPS and CPPS are heavily researched in the past years, there is still no standardized definition for this technology framework (Wu et al., 2020).

According to $\mathrm{Wu}$ et al. (2020), the most accepted definition can be derived from the work of Cardin (2019) who extended a previous definition from Monostori et al. (2016) to the following statements:

1. CPPS are superordinate systems within systems.

2. CPPS consist of cooperative elements, those connect with each other situationally appropriate, on and between all different levels within the production environment, from 
Table 1 LC user centered CPPS: further adaption and concretization by the authors (Wu et al., 2020)

\begin{tabular}{|c|c|c|}
\hline & Criteria & Concretization \\
\hline I & System in a system & $\begin{array}{l}\text { Data exchange and process adaptions on other upcoming process } \\
\text { steps based on gathered data from the rolling mill through a } \\
\text { unified network layer }\end{array}$ \\
\hline II & $\begin{array}{l}\text { Situationally appropriate connection and data transfer on different } \\
\text { layers }\end{array}$ & $\begin{array}{l}\text { Change in data storage frequency based on actual machine status } \\
\text { (on/off) and state dependent data publishing route within the layer } \\
\text { system }\end{array}$ \\
\hline III & Enhance decision making process in real time and state dependent & $\begin{array}{l}\text { Implementation of a machine learning algorithm that predicts } \\
\text { results of the actual process step and upcoming process steps in } \\
\text { near real time including the capability of adaption of the } \\
\text { prediction due to foreseen and unforeseen events }\end{array}$ \\
\hline IV & User centered GUI & $\begin{array}{l}\text { Two user friendly front end and two (IT-skilled) user friendly back } \\
\text { end interfaces }\end{array}$ \\
\hline V & LC and resilient design & $\begin{array}{l}\text { Finding the optimum of cost-effective } \mathrm{HW} \text { and } \mathrm{SW} \text { solutions under } \\
\text { the restriction of resilient, robust and easy to use solutions }\end{array}$ \\
\hline
\end{tabular}

the processes itself, through involved machines up to overlaying networks, e.g. MES or ERP-systems.

3. CPPS enhance decision making processes in real-time in a resilient and robust way, with respect to time as well as foreseen and unforeseen events (Wu et al., 2020).

The fulfillment of (1), (2) and (3) for the case study presented in this paper will be demonstrated in the following chapters. In order to do so, these very broad conditions have to be concretized. Despite this requirements, the practicability for learning purposes as well as financial restrictions (e.g. for the implementation in a SME or academic learning environment) were considered. Most important, the user friendliness of a CPPS will also be in focus of this study. Therefore, the development of shop-floor friendly, intuitive Human Machine Interfaces (HMIs) are a central point in this work. Additionally, LC solutions to avoid expensive maintenance and update plans were used wherever possible. Table 1 summarizes the specifications of the LC user centered CPPS developed within this paper.

\section{Initial machine and digitalization set up}

This chapter describes the initial state of the existing infrastructure at the SFL, whereas (3.1) focusses on the IT-layer structure and (3.2) shows the initial state of the rolling mill system to integrate into the layer architecture.

\section{The six-layer architecture at the SFL}

Figure 3 shows the initial layer system implemented at the SFL. Before the integration of the milling system, a CNC lathe (type EMCOTURN E65) was connected with a power measurement unit into a condition monitoring system, pow- ered by a WAGO controller with integrated warm memory storage (type PFC200 G2 2ETH RS). The unrefined data (e.g. phase currents, voltages) is pre-processed, agglomerated and uploaded on the internal server structure at the SFL, using the structured text (STS) based WAGO e-cockpit SW, after A/D transmission via additional modules (type WAGO 750-494). Within the STS environment, an additional condition monitoring system and corresponding GUI was programmed. The server-stored data is extracted autonomously with a Python based script, running on the same server environment. This script extracts and transforms the data into a set up SQL database, from which most important project management (PM) data is published near real time on a PHP based PM tool (Ralph et al., 2021a, 2021b, 2021c).

The layer architecture was initially created with the purpose of connecting different machine systems at the SFL step by step, including not only condition monitoring and PM-related data, but also process data and, as final objective, resulting in different $\mathrm{LC}$ user centered CPPS. Therefore, the five criteria defined in Table 1 were already considered within the planning and development of this structure (Fig. 3).

\section{The rolling mill system}

The rolling mill system at the SFL at the CMF is a duo rolling mill and was built and put into operation in 1954. The hand wheel at the top of the rolling mill is used to adjust the height of the roll gap (Fig. 4) and rotates the guide spindle via gears, which increases or decreases the height of the rolling gap depending on the direction of rotation. An adjustment of $0.07 \mathrm{~mm}$ per gear tooth was used as a parameter for adjusting the roll gap height.

More than a decade ago, the machine was equipped with two load cells to measure the rolling force on the left and right guide spindle. Figure 5 shows the initial load cell mounted 


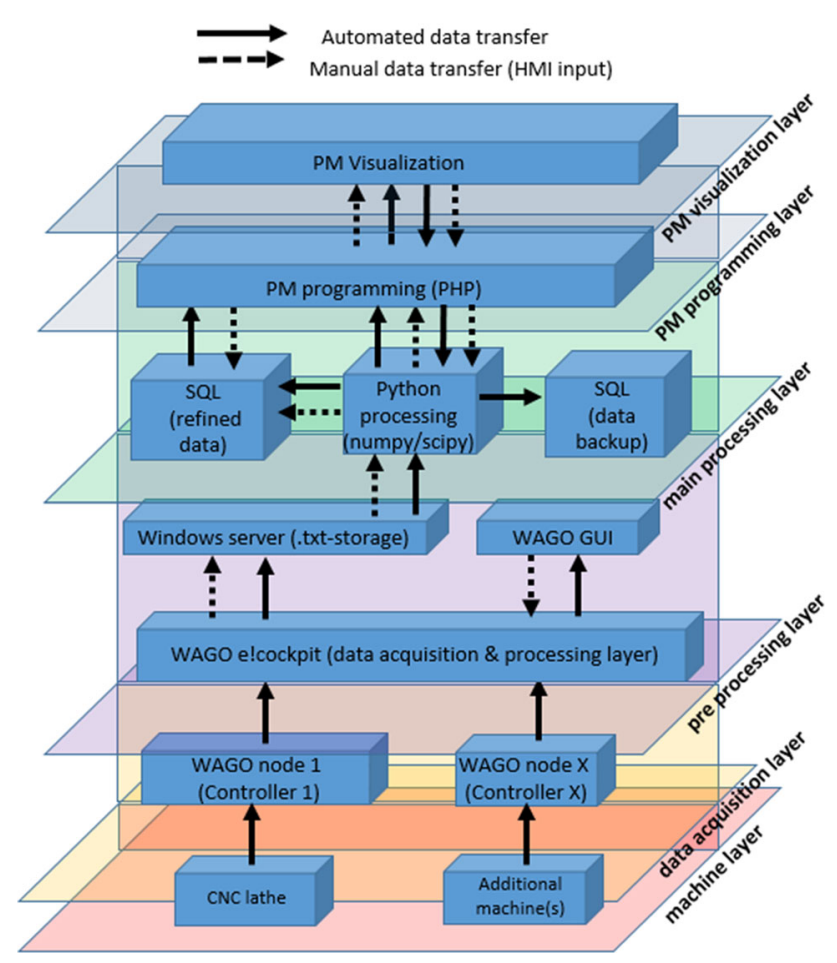

Fig. 3 Initial state of the six-layer architecture at the SFL (Ralph et al., 2021a, 2021b, 2021c)

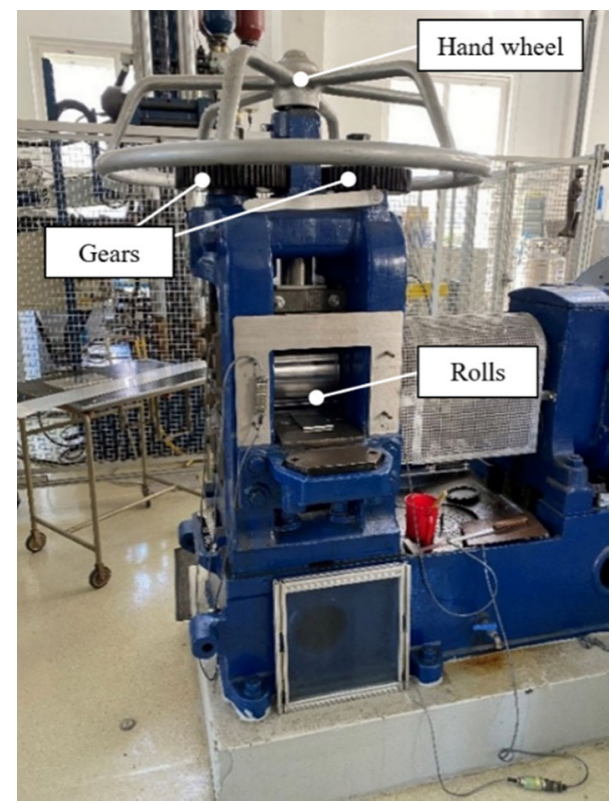

Fig. 4 Rolling mill system: initial state

between the left guide spindle and the roll chock. The data acquisition during a milling process, in order to obtain the actual $F_{R}$ with corresponding time increments, was done with a proprietary Windows XP based DAQ system, with a maximum data transmission frequency of $22.5 \mathrm{~Hz}$.

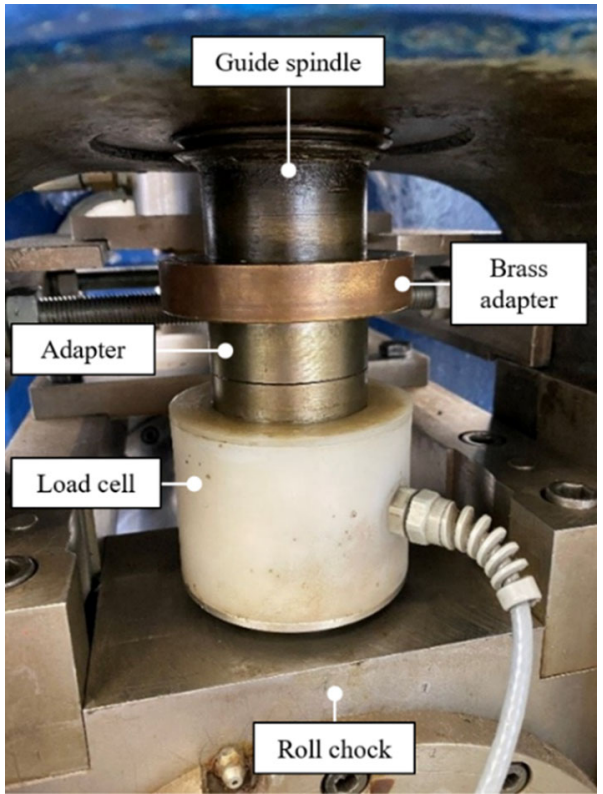

Fig. 5 Load cell of the left guide spindle: initial state

\section{Retrofitting and digitization}

The following subchapters describe the sensor retrofitting (4.1) as well as corresponding digitization (4.2) and therefore coupling of the calibrated sensors to the SFLs six-layer architecture. All actions taken for the sensor selection, calibration and implementation underly the assumptions made in (2.1) (the required physical quantities) and (3.2) (the physical limits of the machine system itself).

\section{Sensor retrofitting}

In order to choose appropriate sensors to meet the criteria of a LC user centered CPPS, the required specifications were defined in first instance. Based on these requirements, the sensor technology was selected. In addition to the required magnitude of the sensors, parameters such as linearity and resolution play a major role in the resulting quality of the recorded data and in the selection of suitable sensor technologies. Furthermore, the maximum resolution of the DAQ system must be taken into account, as in most terms the bottleneck is not the measurement of an analog signal or the signal transfer through an $\mathrm{A} / \mathrm{D}$ converter but the buffering and writing of gathered data on the controlling unit (Fig. 3, data acquisition layer). In order to implement a machine learning algorithm based on Eqs. (1) and (2) and therefore satisfy condition III, Table 2 shows the minimum quantities to be measured to achieve such a system. The measurement range is a result of the rolling mill systems specifications.

For the measurement of $F_{R}$, the already existing load cells had to be replaced, as the maximum measurement range 
Table 2 Quantities and corresponding range to be measured to ensure valid data gathering within the required operational range

\begin{tabular}{ll}
\hline System parameter & Measurement range \\
\hline $\mathrm{F}_{\mathrm{R}}$ & $0-400 \mathrm{kN}$ \\
$\mathrm{s}_{0}$ & $0-20 \mathrm{~mm}$ \\
\hline
\end{tabular}

of each cell was defined with $150 \mathrm{kN}$. Furthermore, after calibration and analysis of the resulting data, a significant deviation between both cells and high non-linearity in each measurement system was detected, indicating a malfunction within at least one of them.

For the new load cell measurement system, despite the specified range, the following requirements had to be fulfilled:

a. The measuring system must be able to withstand an overload to avoid measuring errors and shortened lifespan (Table 1, V).

b. The load cells must have a high linearity in order to be able to resolve the rolling force to a sufficient degree during the rolling process (Table 1) (III).

Additionally, the initial roll gap $\mathrm{s}_{0}$ and with it, the change of the gap during the rolling process had to be measured with sufficient linearity and within the defined range. Based on heuristic knowledge and basic calculations, the deflection of the roll gap could be defined in the range of tenths of a millimeter, while the maximum height of the roll gap is constricted by the machines' geometry to $20 \mathrm{~mm}$. Since the linearity of a sensor is specified as a percentage of the measuring range, two conditions must be met:

c. The sensor must be able to measure a distance greater than the maximum adjustable roll gap and

d. must have a high linearity in order to be able to resolve the deflection of the roll gap to a sufficient degree during rolling (Table 1, III).

To meet the requirements of (c), (d), and the defined measurement range in a cost-effective manner (Table 1, I), a linear variable differential transformer (LVDT) sensor was chosen. In addition, an angle sensor was attached to the gear of the hand wheel for demonstration purposes to students and other interested parties at the SFL.
Table 4 External electronics and specifications from the sensors to be implemented

\begin{tabular}{llll}
\hline External electronics & Type & Sensor & Output \\
\hline PR electronics 2261 & $\mathrm{mV}$ transmitter & Load cell & $0-20 \mathrm{~mA}$ \\
Waycon LV-S-25- & $\begin{array}{c}\text { Integrated electronic } \\
\text { (n/a) }\end{array}$ & LVDT & $4-20 \mathrm{~mA}$ \\
300-KA05-L10 & & & \\
\hline
\end{tabular}

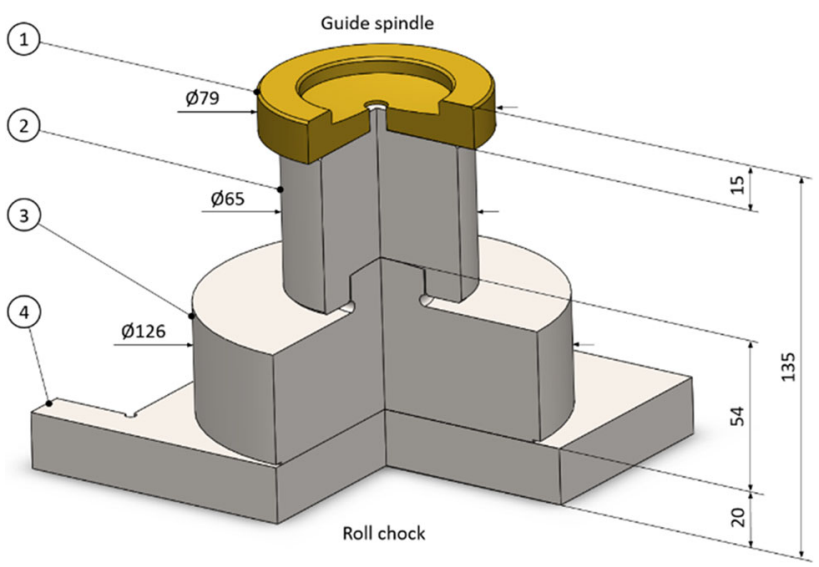

Fig. 6 Construction scheme of the new designed load measurement unit

Table 3 shows the finally selected sensors and their specifications.

Table 4 defines the external electronics used to transfer the sensor signals into a suitable analog signal for the DAQ system. For the LVDT sensor, the external electronics from the same manufacturer was used. External electronics from a third-party supplier were installed for the load cells. These $\mathrm{mV}$ transmitters can be individually configured to the specifications and requirements of the load cell and can therefore also be used if the load cells are replaced.

In order to mount the selected sensors on the rolling mill, mechanical adaptions had to be made. Since the diameter of the new load cells is larger than the width of the roller supports, the entire contact surface at the bottom of the load cell cannot be supported. This could lead to a falsification of the measurement results. In order to be able to use the entire contact surface of the new load cell, an intermediate plate was installed between the roll chock and the load cell. To connect the guide spindle with the load cell, an additional adaptor was designed to transmit the rolling force coaxially (Figs. 6, 7).
Table 3 Selected sensors and their specifications for the transformation of the rolling mill system according to the fundamental equations pointed out in Sect. 2

\begin{tabular}{lllll}
\hline Sensor & Type & Range & Linearity & Output signal \\
\hline Kern CR 20000-1Q1 & Load cell & $0-200 \mathrm{kN}$ & $0.1 \%$ & $2 \mathrm{mV} / \mathrm{V}$ \\
Waycon & LVDT & $0-25 \mathrm{~mm}$ & $0.1 \%$ & $\mathrm{n} / \mathrm{a}$ \\
LV-S-25-300-KA05-L10 & & & & \\
ASM PH36 & Magnetic multiturn encoder & $31 \times 360^{\circ}$ & $\pm\left(2^{\circ}+0.015 \%\right)$ & $4-20 \mathrm{~mA}$ \\
\hline
\end{tabular}




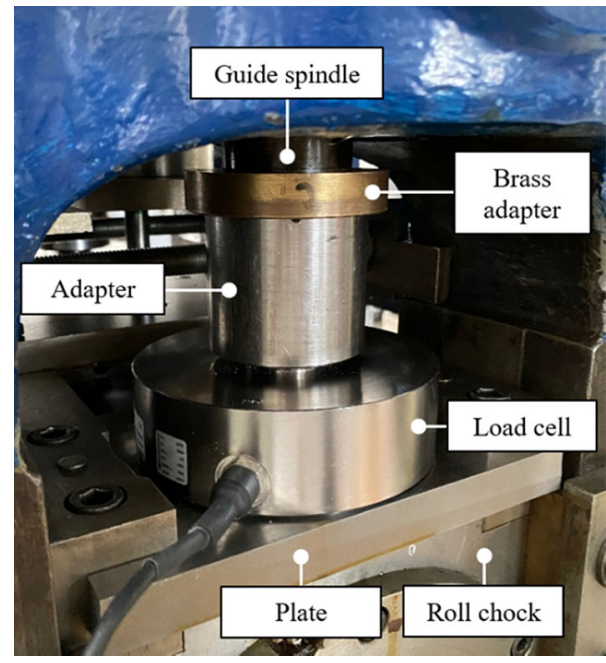

Fig. 7 Resulting implementation of the new designed load measurement unit

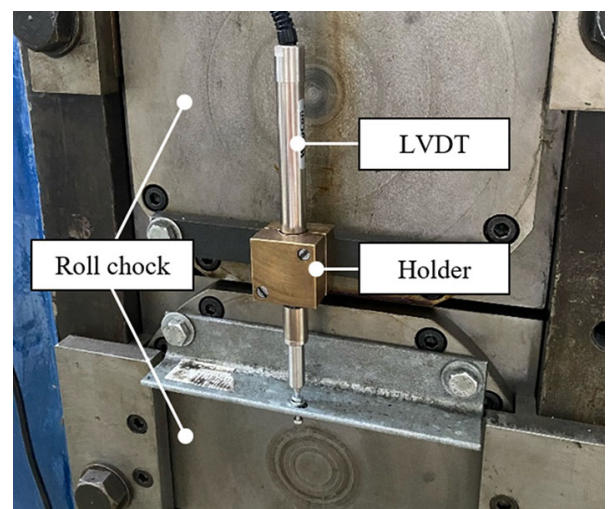

Fig. 8 Mounted LVDT sensor

The LVDT sensor was mounted between the two roll chocks. In order to prevent interferences with the inductive measuring principle, the sensor holder is made of nonmagnetic material (Fig. 8).

The multiturn encoder was mounted directly on the machine rack. The resulting angle after manual roll gap changing is derived via the connection of the sensor with one of the two main gears at the mill, which are connected to the hand wheel via a defined gear transmission ratio. To consider the surface roughness of the gear and therefore ensure contact between the sensor and the gear, a pre-stressed spring is applied to ensure continuous contact (Fig. 9).

\section{Digitization}

In order to convert the analog signals from the external electronics (Table 4) into signals suitable for computer-aided processing, the devices were connected to the already existing WAGO node 1 (Fig. 3, data acquisition layer). This node consists of a WAGO PFC200 G2 2ETH RS controller coupled

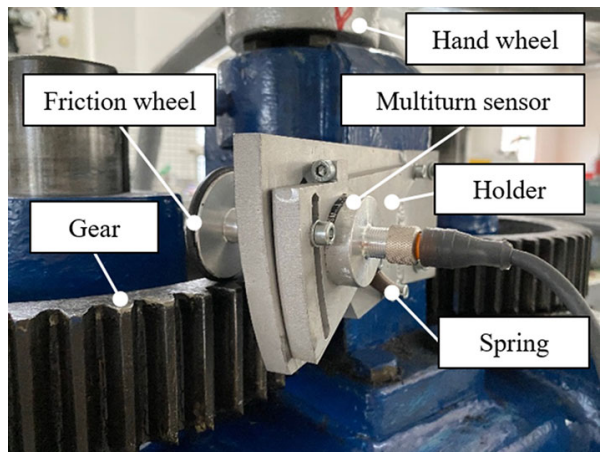

Fig. 9 Mounted multiturn encoder

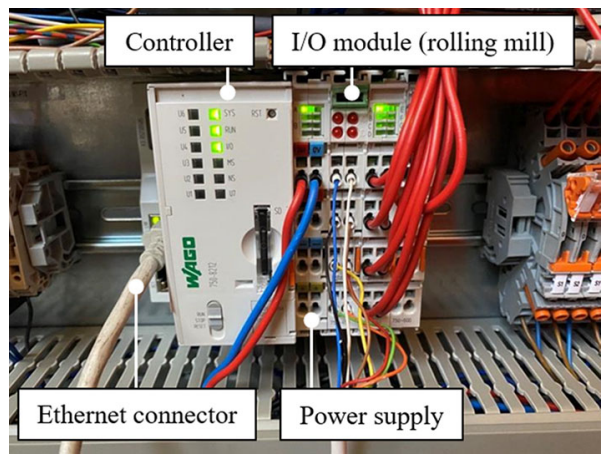

Fig. 10 Controller and I/O modules

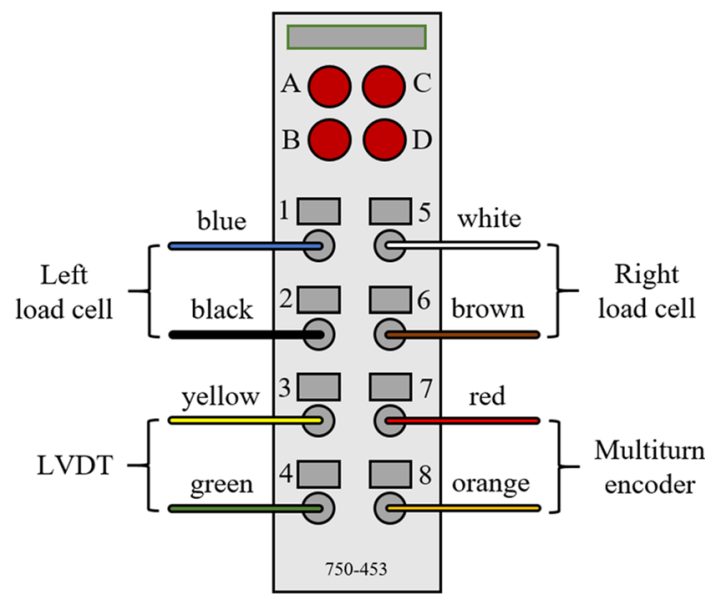

Fig. 11 Circuit diagram of the connection rolling mill sensors/DAQ

with I/O modules (Fig. 10). The I/O modules used are from the same supplier (type 750-453) and are designed for transforming analog signals in the range of 0 to $20 \mathrm{~mA}$. As already mentioned, the resolution depends on the DAQ, which can resolve the analog signals of the sensors in $15 \mathrm{bit}$, therefore the analog signal of each sensor can be resolved in $2^{15}$ equivalent steps.

Figure 11 shows the corresponding connections of the three mill sensors with the used I/O module. 


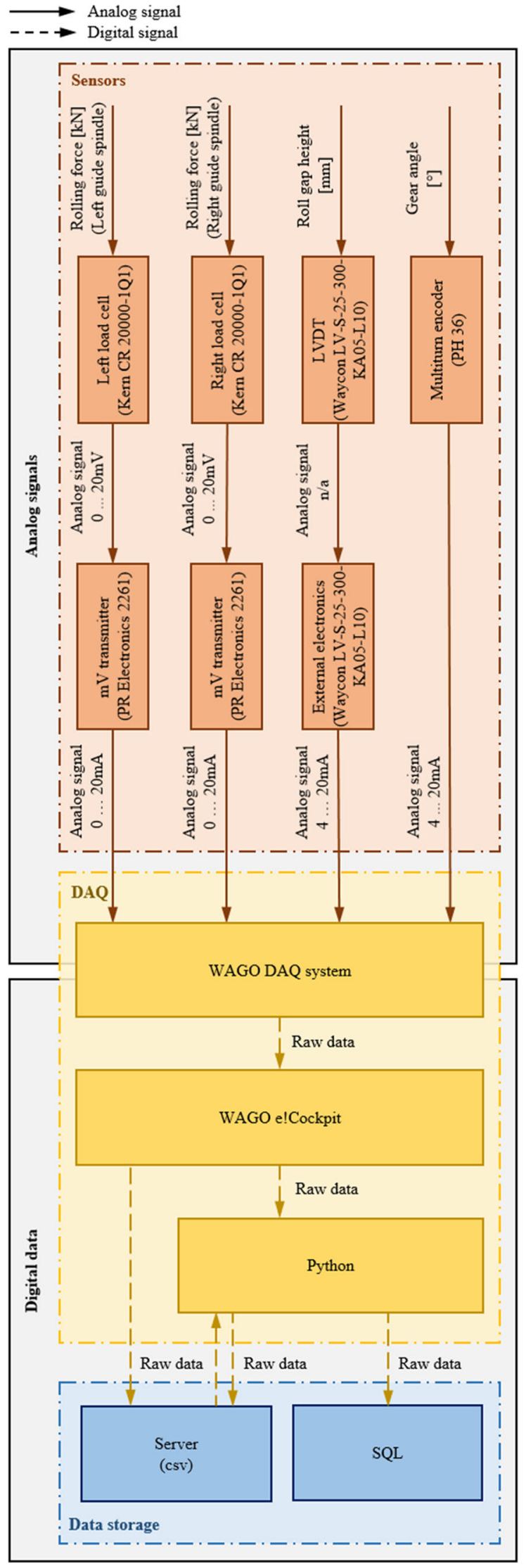

Fig. 12 Sensor connection and A/D conversion

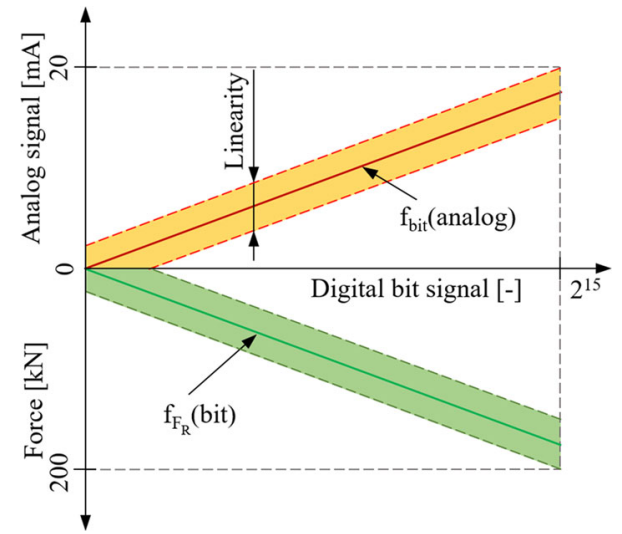

Fig. $13 \mathrm{~A} / \mathrm{D}$ input signal to physical quantity transformation: example rolling mill

\begin{tabular}{|c|c|}
\hline Back & Rolling mill \\
\hline total load & 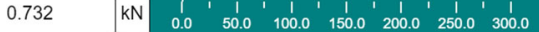 \\
\hline max load until reset & 1.123 \\
\hline left load cell & 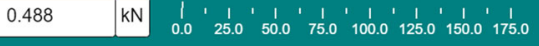 \\
\hline right load cell & 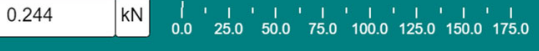 \\
\hline roll gap & 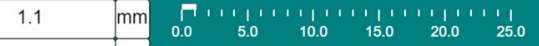 \\
\hline hax roll gap until rese & 1.12 \\
\hline angle sensor & $\begin{array}{cccccccccc}0 & 1 & 1 & 1 & 1 & 1 & 1 & 1 & 1 \\
0.0 & 720.0 & 1440.0 & 2160.0 & 2880.0 & 3600.0\end{array}$ \\
\hline Max Reset & RUN MEASUREMENT (0) \\
\hline
\end{tabular}

Fig. 14 Rolling mill layer of the WAGO GUI

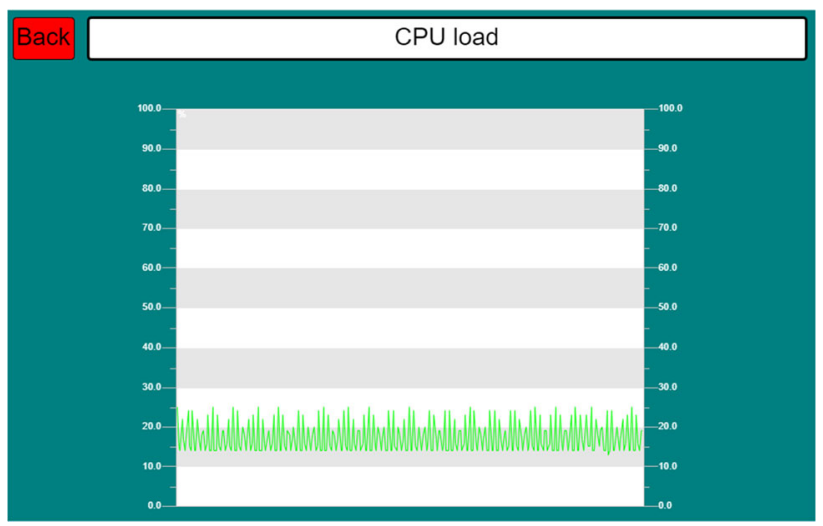

Fig. 15 CPU load layer of Node 1: connected machines turned off

Figure 12 shows the final digitization framework for all three sensor types, from the physical measurement entity to the implementation into the layer framework. It is important to note that the used WAGO DAQ system isn't the most cost efficient possibility to connect the machine within such a system (e.g. Arduino based microcontroller would have been a more LC alternative). Under consideration of practicability and longtime maintainability, the use of a stan- 
Table 5 Coefficients for the linear characteristic curve of implemented sensors according to Tables 3 and 4

\begin{tabular}{llll}
\hline Physical quantity & $\mathrm{a}$ & $\mathrm{b}$ & Range \\
\hline $\mathrm{F}_{\mathrm{R}}(\mathrm{kN})$ & 0.0 & $6.104 \mathrm{E}-3$ & $0-200 \mathrm{kN}$ \\
$\mathrm{s}_{0}, \mathrm{~s}_{1}(\mathrm{~mm})$ & $6.5536 \mathrm{E}+3$ & $9.537 \mathrm{E}-4$ & $0-25 \mathrm{~mm}$ \\
$\operatorname{deg}\left({ }^{\circ}\right)$ & $6.5536 \mathrm{E}+3$ & $4.257 \mathrm{E}-1$ & $0-31 \times 360^{\circ}$ \\
\hline
\end{tabular}

dardized framework which operates on industrial standards like the WAGO system or other comparable solutions was chosen. Another reason for this decision is the user friendly back end GUI, that comes within the SW and that allows non IT-personnel to supervise and even extend programmed functionalities with basic IT knowledge (e.g. the usage of predefined module blocks within the SW instead of STS coding). This advantages also apply for the first developed front end GUI, which is also based on the same framework.

\section{Digitalization}

This chapter describes the transformation of digitalized sensor data within the layer architecture. After A/D conversion, resulting digital signals have to be transformed into real physical quantities. This is done within the data preprocessing layer (Fig. 3) using STS based programming and an additional Python script. Additionally, state dependent data gathering frequency is set within this layer (5.1), fullfilling the requirements of I and II (Table 1). (5.2) describes the adaption of the first front-end GUI for the rolling mill setup (according to Table 1, IV).

\section{Data pre-processing layer}

Before working with the digitized signal data is possible, transformation of the resulting data into corresponding physical quantities has to be done. This operation is carried out within the data pre-processing layer (Fig. 3) using the STS environment provided by the WAGO SW. All three sensor types can be calibrated linearly under consideration of their characteristic linearity (Table 3 ). As a result, a linear equation was programmed for each input channel, whereas the two individual coefficients were derived as a result of the range restriction of the specific device.

$$
f(\text { physicalquantity })=a+b * \text { bit_value }
$$

Figure 13 visualizes the transformation of the current signal into its physical value on the example of the load cells used schematically.

Table 5 displays the resulting coefficients for all three sensor types on the basis of Eq. (4).
The resulting $F_{R}$ is then obtained summarizing the values from both load cells within the STS environment. This approach also ensures that eccentric sheet insertion can be measured and do not result in a higher measurement error.

To fulfill requirement II. (Table 1), two different sampling rates for all rolling mill channels were defined. The first one is enabled continuously. In this case, $1 \mathrm{~Hz}$ was set within the STS. This low frequency is used to work as a simple condition monitoring system, giving warnings over the WAGO GUI (Sect. 5.2) whenever sensor values are out of calibrated range. For the actual processing, via a trigger that can be manually turned on within the GUI, a sampling frequency of $500 \mathrm{~Hz}$ was determined. In this case a Boolean variable is turned TRUE, which activates the higher rate, whereas the lower frequency stays enabled. After the actual process, the user can end the measurement again manually through the GUI, which sets the Boolean equal FALSE again. The major advantage through the manual activation is the possibility of measuring unconventional processes or trials, which would not be measured if the higher sampling rate would be activated by a force or dilation triggered algorithm (e.g. very thin sheets with low resulting $F_{R}$, very soft material with low $\Delta \mathrm{s})$. While the continuous data gathered is directly stored on the CMFs' internal server, the actual $500 \mathrm{~Hz}$ measurements have to be refined additionally before data science and machine learning algorithms can be used on it. This refinement algorithm is carried out within a simple Python script, which deletes numerical artefacts and duplicates from the given raw data. Numerical artefacts are lines that may occur due to buffering issues on the used controller unit. As the controller is initially not able to obtain frequency rates above $100 \mathrm{~Hz}$, a script that uses the controllers' RAM instead of warm memory was written and implemented in the STS environment. Nevertheless, the buffering operation stores data points until a defined extend, before submitting these data points to be actually written on the controllers' internal memory. During the writing process, doubled data points within the same time stamp occur. Additionally, lines with zeros or $\mathrm{NaN}$ values are a result of this procedure. To avoid errors at upcoming mathematical operations $(6.2,6.3)$, these data points and corresponding rows have to be filtered first.

\section{WAGO based GUI}

The already existing WAGO GUI was extended with an additional layer for the rolling mill system, taking into account the preferences of involved technicians on the shop-floor level. The GUI runs on the controlling unit and is available through the corresponding IPv4 address with all computing devices within the SFL network. Figure 14 shows the STS programmed rolling mill layer within the GUI. Additional to the two resulting loading force values and sum of both, another variable is visualized, which is named "max load until reset". 
This variable returns the maximum value stored at a current measurement. If the "Max Reset" button is pressed, the variable is set to 0 . The same function is given for the variable "max roll gap until reset", to be able to see the maximum height and force within a measurement, whereas all other variables defined return the real time value from the respective sensors. Depending on the status of the Boolean "Run Measurement", the sampling rate is whether $1 \mathrm{~Hz}$ (Boolean $=$ FALSE, button $=$ GREEN (Fig. 14) or $500 \mathrm{~Hz}$ (Boolean $=$ TRUE, button $=$ RED). The parenthesized integer next is coupled with a counter in the STS, which counts up for each measurement executed within the same day. If the day within the timestamp changes, the counter is reset to 0 . As the automatic export of high frequency measurement data is done in single files, named "YEAR-MONTH-TRIAL-NR", the Python filter algorithm can easily distinguish between appending files within the defined folder. In order to prevent overloading of the rolling stand and power train, the visualization of force only contains a range of $0-300 \mathrm{kN}$. This ensures that the aggregate is not permanently operated at its load limit.

As mentioned in 5.2, the data storage from the $\mathrm{I} / \mathrm{O}$ module is executed directly in the hot memory of the controller. Therefore, another layer was developed, which shows the actual CPU load of the respective controller. If this load exceeds $60 \%$, writing and therefore accurate data gathering from connected sensors cannot be guaranteed. This value is reached within this setup if both connected aggregates are activated and the sampling frequency of the rolling mill exceeds about $0.560 \mathrm{kHz}$. If $60 \%$ are reached, another Boolean in the STS is set TRUE and a warning signal is shown at the main display. Figure 15 shows the CPU load GUI both connected machines disabled.

\section{Machine learning algorithm and decision enhancing digital twin}

After successful digitization (4) and digitalization (Sect. 5), III. (Table 1) has to be fulfilled. For this purpose, the connected rolling mill system had to be equipped with a suitable and efficient algorithm to support decision making within the milling process. As the correlation between the most important variables (Sect. 2.1) is rather complex in practice, a data driven modelling approach was chosen in first instance. This data driven model should be resilient, robust and easy to understand. Therefore, the complex and non-linear realphysical interrelationships between the machine system and processed material were discretized and transformed into a system of interdependent linear equations, calculated within the Python environment (Sect. 6.4). To avoid unrealistic or unreproducible results, a statistical approach was chosen (Sect. 6.1). Additionally, as the focus in this work lies on the
Table 6 Defined rolling schedules for data gathering, from high height reduction per process step $\left(\mathrm{V}_{1}\right)$ to moderate $\left(\mathrm{V}_{3}\right)$

\begin{tabular}{llll}
\hline $\mathrm{Nr}$ & $\mathrm{s}_{0}\left(\mathrm{~V}_{1}\right)(\mathrm{mm})$ & $\mathrm{s}_{0}\left(\mathrm{~V}_{2}\right)(\mathrm{mm})$ & $\mathrm{s}_{0}\left(\mathrm{~V}_{3}\right)(\mathrm{mm})$ \\
\hline 1 & 4.50 & 5.00 & 5.00 \\
2 & 3.50 & 4.00 & 4.50 \\
3 & 2.75 & 3.50 & 4.00 \\
4 & 1.75 & 2.50 & 3.50 \\
5 & 1.00 & 1.50 & 3.00 \\
6 & 0.75 & 1.00 & 2.50 \\
7 & 0.50 & 0.50 & 2.00 \\
8 & - & - & 1.50 \\
9 & - & - & 1.00 \\
10 & - & - & 0.50 \\
\hline
\end{tabular}

calibration of the stand module $\mathrm{C}$ with all relevant dependencies, a well characterized material (Sect. 6.2) was chosen for the first setup. As a result, the second front-end GUI mentioned initially in this paper is presented and explained (Sect. 6.5).

\section{Experimental setup}

According to hypothesis 1 and 2 (2.1), the stand module $\mathrm{C}$ is a function of the processed sheet width $\mathrm{b}$ as well as $\Delta \mathrm{h}$ and $\mathrm{s}_{0}$. Despite this statement, another important influencing factor in practice is the usage of an appropriate lubricant. Therefore, the following dependencies have been investigated within this experiment:

$C=C\left(s_{0}, b, \Delta h, \mu_{\text {lubricant }}\right)$

For the initial calibration, $\mu_{\text {lubricant }}$ describes the change between sufficient lubrication and no lubrication. To be able to develop a data driven prediction model for the rolling process, three different rolling schedules $\left(\mathrm{V}_{1}, \mathrm{~V}_{2}\right.$ and $\left.\mathrm{V}_{3}\right)$ were defined (Table 6). The main objective of this setup was to get a broad set of data points for different $\mathrm{s}_{0}(\Delta \mathrm{h})$, to investigate the influence of different combinations of these variables. To ensure comparability, an initial thickness of $6 \mathrm{~mm}$ and a final $\mathrm{s}_{0}$ of $0.5 \mathrm{~mm}$ was defined for each rolling schedule.

By varying the rolling schedules according to Table 6 , it is possible to investigate if different cumulated strain paths (Eq. 6) have an influence on the elastic behaviour of the mill stand and therefore $\mathrm{C}$.

$C\left(\Delta h_{i j}, s_{0_{k}}\right)=! C\left(\Delta h_{l m}, s_{0_{n}}\right)$

For the investigation of the influence of $b$, three widths for the initial test and calibration data setup were chosen. For the validation of the resulting equation system, two additional widths were defined, one between the three first and one 
Table 7 Defined sheet widths and corresponding rolling schedules for data gathering

\begin{tabular}{lcll}
\hline $\mathrm{Nr}$ & Width $(\mathrm{mm})$ & Test/calibration & Validation \\
\hline $\mathrm{B}_{1}$ & 150.00 & $\mathrm{X}$ & \\
$\mathrm{B}_{2}$ & 100.00 & $\mathrm{X}$ & \\
$\mathrm{B}_{3}$ & 50.00 & $\mathrm{X}$ & \\
$\mathrm{B}_{4}$ & 74.50 & & Interpolation \\
$\mathrm{B}_{5}$ & 30.10 & & Extrapolation \\
\hline
\end{tabular}

Table 8 Defined lubrication schemes for the corresponding rolling schedules and sheet widths defined in Tables 6 and 7

\begin{tabular}{ll}
\hline Test series & Description \\
\hline $\mathrm{T}_{1}$ & Full lubrication \\
$\mathrm{T}_{2}$ & No lubrication \\
\hline
\end{tabular}

out of initial range, to be able to proof interpolation as well as extrapolation capabilities of the system (Table 7). For this validation experiments, rolling steps $1-4$ from $V_{1}$ were used, followed by a direct height reduction from 1.75 to $0.75 \mathrm{~mm}$ (Table $6, \mathrm{~s}_{0}\left(\mathrm{~V}_{1}\right)$ ). The fifth step was spared out to be able to see if the interpolation between known $\mathrm{s}_{0}$ would obtain valid results within the developed machine learning algorithm.

To investigate the influence of lubrication on $\mathrm{C}$, two different test series were defined, whereas test and calibration data sets were mirrored for both process friction states (Table 8).

The sheet specimen for the rolling process has to be entered manually (Fig. 4). To avoid measuring errors due to deviations in the reproducibility of single process steps within the rolling schedule, a statistical approach has been chosen. For this experiment, twelve sheets for each tested rolling schedule, test series and width were cut out of two identical raw sheets. In sum, 216 sheets for the creation of test and calibration data were used, split into three different rolling schedules, three different widths and to different test series (Table 9). To ensure a smooth transition into the milling system, the initial length of each specimen was set to $135 \mathrm{~mm}$. Additionally, each sheet was deburred and cleaned before treatment.

The configuration shown in Table 9 for each test series ensures a continuous reduction of $\mathrm{s}_{0}$. In sum, 1736 milling process steps were carried out to gather the required test and calibration data. Figure 16 shows the processed specimens before and after rolling.

Table 10 shows the setup for the gathering of validation data. For this purpose, only 36 additional specimens were used and processed within $\mathrm{T}_{1}$ (no lubrication) and rolling schedule $\mathrm{V}_{1}$, whereas back up material was kept if the validation attempt in the resulting algorithm would fail. Including all process steps, a total of 1904 milling operations delivered output for the data driven modelling of the corresponding machine learning algorithm (Sect. 6.4).
Table 9 Specimen classification: resulting executed rolling schedules for the gathering of test/calibration data

\begin{tabular}{llll}
\hline Test series & Specimen $\mathrm{nr}$ & Rolling schedule & Sheet width \\
\hline $\mathrm{T}_{1}$ & $1-12$ & $\mathrm{~V}_{2}$ & $\mathrm{~B}_{1}$ \\
& $13-24$ & $\mathrm{~V}_{3}$ & $\mathrm{~B}_{1}$ \\
& $25-36$ & $\mathrm{~V}_{2}$ & $\mathrm{~B}_{2}$ \\
& $37-48$ & $\mathrm{~V}_{3}$ & $\mathrm{~B}_{2}$ \\
& $49-60$ & $\mathrm{~V}_{2}$ & $\mathrm{~B}_{3}$ \\
& $61-72$ & $\mathrm{~V}_{3}$ & $\mathrm{~B}_{3}$ \\
& $73-84$ & $\mathrm{~V}_{1}$ & $\mathrm{~B}_{1}$ \\
& $85-96$ & $\mathrm{~V}_{1}$ & $\mathrm{~B}_{2}$ \\
& $97-108$ & $\mathrm{~V}_{1}$ & $\mathrm{~B}_{3}$ \\
$1-12$ & $\mathrm{~V}_{2}$ & $\mathrm{~B}_{1}$ \\
$\mathrm{~T}_{2}$ & $\mathrm{~V}_{3}$ & $\mathrm{~B}_{1}$ \\
& $13-24$ & $\mathrm{~V}_{2}$ & $\mathrm{~B}_{2}$ \\
& $25-36$ & $\mathrm{~V}_{3}$ & $\mathrm{~B}_{2}$ \\
& $37-48$ & $\mathrm{~V}_{2}$ & $\mathrm{~B}_{3}$ \\
& $49-60$ & $\mathrm{~V}_{3}$ & $\mathrm{~B}_{3}$ \\
& $61-72$ & $\mathrm{~V}_{1}$ & $\mathrm{~B}_{1}$ \\
$73-84$ & $\mathrm{~V}_{1}$ & $\mathrm{~B}_{2}$ \\
& $85-96$ & $\mathrm{~V}_{1}$ & $\mathrm{~B}_{3}$ \\
\hline $97-108$ & &
\end{tabular}

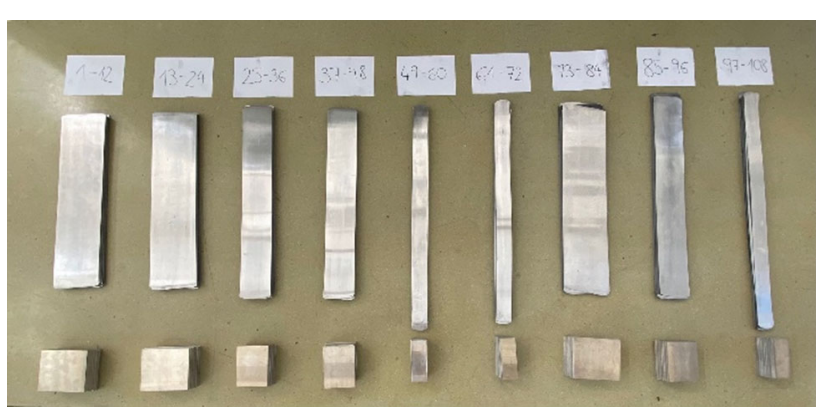

Fig. 16 Processed sheet specimens: rolled (T1, top); initial (T2, bottom)

Table 10 Specimen classification: rolling schedule, corresponding lubrication scheme and sheet with for the validation data

\begin{tabular}{llll}
\hline Test series & Specimen $\mathrm{nr}$ & Rolling schedule & Sheet width \\
\hline $\mathrm{T}_{2}$ & $109-124$ & $\mathrm{~V}_{1}$ & $\mathrm{~B}_{4}$ \\
(validation) & $125-144$ & $\mathrm{~V}_{1}$ & $\mathrm{~B}_{5}$ \\
\hline
\end{tabular}

\section{Deformation behavior of used material under rolling conditions}

The material used in this study is EN AW-1050A, also referred to as $\mathrm{Al}$ 99.5, which is considered as technically pure aluminum due to its low content of constituents. Pure aluminum shows excellent ductility, exhibiting exceptionally good deformation behavior even after severe cold working. The hardening of the material introduced by forming can be attributed to the introduction and the multiplication of 
dislocations during their migration. For deformations such as in a cold rolling process, the face-centered cubic (fcc) crystal structure determines the slip systems: primarily, slip is observed on $\{111\}<110>$-slip systems since the Peierl's stress is lowest in this direction. The stacking fault energy of about $170 \mathrm{mJm}^{-2}$ in pure aluminum, which is comparatively high for fcc-structured metals, determines the predominant deformation mechanism of slip, rather than developing deformation twins (Simon, 1979).

The increase in strength introduced by cold working can be described in terms of increasing dislocation density. As a rough estimate, the dislocation density can be approximated by the increase in strength using Eq. (7).

$\sigma=0.5 G b \rho^{\frac{1}{2}}$

In Eq. (7), $\sigma$ is referred to as the strength, $G$ is the shear modulus of the respective material, $b$ is the burgers vector and $\rho$ is the dislocation density. The higher the dislocation density, the lower the mean free path between the dislocations. As a result of their interaction, strength increases due to reduced mobility. The dislocation increase depends on the selected forming degrees, which are introduced into the material at certain height reductions $\Delta \mathrm{h}$ due to the rolling schedule. This increase in dislocations is opposed by certain softening processes since the condition including a high dislocation density is thermodynamically unstable. The most essential softening mechanisms represent recrystallization and recovery, the latter being crucial for aluminum due to the high stacking fault energy. For recrystallization to occur, both a critical degree of deformation and an elevated temperature of about $40 \%$ of the melting temperature are required, whereas both conditions are not met within this experimental setup (Gottstein, 2004).

During the rolling of a pure aluminum sheet, part of the applied forming energy is stored as deformation energy, the other, much larger part, dissipates in heat, driven by two phenomena: (1) the plastic deformation itself and resulting internal friction and (2) caused by tribological effects at the interface between the rolls and the sheet metal or the lubricant. These conditions favor the recovery processes which are characterized by facilitated cross-slipping of screw dislocations and climbing of step dislocations, thus causing annihilation of dislocations and therefore decreasing the dislocation density and the effect of cold working. These softening processes are diffusion-dependent, which occur at an accelerated rate under temperature increase, although room temperature is already sufficient to continue these processes to equilibrium when considering pure aluminum (Hasegawa \& Kocks, 1979).

Therefore, strengthening due to cold working is already reduced at short time periods, leading to the conclusion that these processes do not have an effect on the corresponding
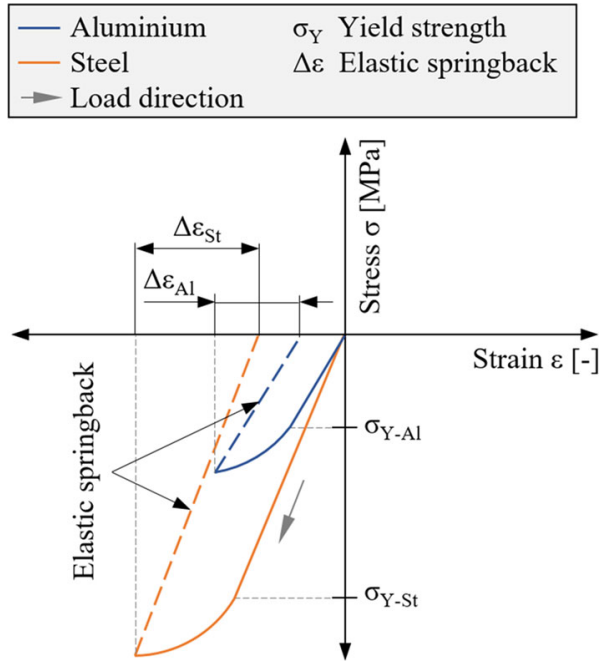

Fig. 17 Elastic stiffness and corresponding effect on $\mathrm{h}_{1}$ during rolling

strength values. Despite the recovery effect, the heat transfer within the tribology system is of utmost importance for the rolling process within this case study.

Aluminum is furthermore characterized by its high thermal conductivity, which at approximately $220 \mathrm{~W}(\mathrm{mK})^{-1}$ exceeds that of conventional steel grades by a factor of three. For this reason, the dissipated forming heat and heat generated by friction between the rolls and the sheet surface spreads rapidly over the entire specimen. As a result, the heat is more easily transferred to the lubricant and dissipated in this fluid. This phenomenon can have a substantial influence on the resulting behavior of the rolled specimen, especially considering different friction states (Ostermann, 2014).

Despite cold work hardening and thermal expansion, the elastic properties of the used material significantly contribute to the resulting process parameters in rolling. After the force is locally removed from the processed specimen, the elastic component of the strain applied results in an increase of the thickness $h_{1}$. As a result, materials with a lower Young's Modulus (YM) are increasing height after rolling significantly more than stiffer materials (Fig. 17).

\section{Resulting experimental data}

As expected from plastic deformation fundamentals, the resulting geometry changes of the tested specimens after rolling varies. The maximum bearable local plastic deformation wasn't exceeded at any specimen within the experiment, therefore the law of constant volume (Eq. 8) applies.

$\ln \frac{l_{1}}{l_{0}}+\ln \frac{b_{1}}{b_{0}}+\ln \frac{h_{1}}{h_{0}}=\varphi_{l}+\varphi_{b}+\varphi_{h}=1$

According to Eq. (8), $l_{1}$ can be obtained if $b_{1}$ and $h_{1}$ as well as the initial geometry is known. Before the resulting 


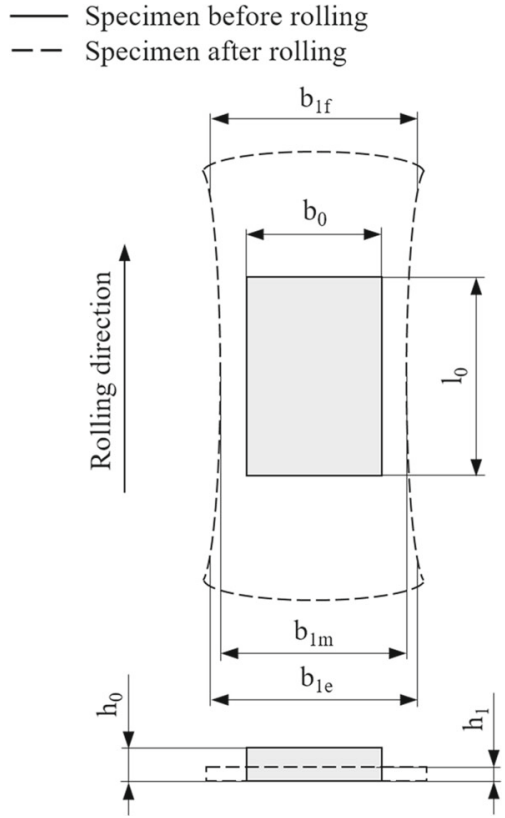

Fig. 18 Sheet width measurement after rolling

test and calibration data is analyzed from a black box point of view, a first indication about whether there is a difference between the two data series can be made after measuring the resulting sheet width of each specimen. This was made on three reproducible locations at each specimen, according to Fig. 18. Table 11 shows the mean value at each measured point for each calibration and validation series, additionally divided into test series $T_{1}$ and $T_{2}$.

As visualized in Table 11, the highest deviation in sheet width is $0.36 \%$, which leads the authors to the statement that no differentiation between test and calibration data can be made. This also supports the theory, that the population of investigated specimens is valid. According to Sect. 6.2 and from a materials science point of view, there should also be no significant difference between sheets of same initial width that were rolled in different rolling schedules. Table 12 shows the standard deviation of all widths within a test series $\left(\mathrm{V}_{1}\right.$, $\mathrm{V}_{2}$ and $\mathrm{V}_{3}$ ).

\section{Additional material related tests}

To ensure that the definition of a CPPS according to Table 1 is fulfilled, additional validations were carried out (Condition III and V). The higher deviation between $\mathrm{T}_{1}$ and $\mathrm{T}_{2}$ within the same width indicates differences between the two test series, which, according to the authors, is the result of a changed tribology system. To investigate if this change significantly contributes to the resulting material behavior, tensile tests were carried out additionally. In order to characterize the mechanical anisotropy of the rolled sheets properly, a small but normed geometry was chosen to obtain stress-s-
Table 11 Specimen classification: resulting sheet widths of the exectuded rolling processes, measured at three points per sheet (test/calibration data)

\begin{tabular}{|c|c|c|c|c|}
\hline $\mathrm{T}_{1}$ & Specimen nr & $b_{1 f}(m m)$ & $\mathrm{b}_{1 \mathrm{~m}}(\mathrm{~mm})$ & $\mathrm{b}_{1 \mathrm{e}}(\mathrm{mm})$ \\
\hline Test data & $1-6$ & 150.93 & 150.82 & 150.95 \\
\hline Calibr. data & $7-12$ & 151.10 & 150.84 & 151.13 \\
\hline Dev. [\%] & & 0.11 & 0.01 & 0.12 \\
\hline Test data & $13-18$ & 151.02 & 150.90 & 151.02 \\
\hline Calibr. data & $19-24$ & 151.08 & 150.90 & 151.15 \\
\hline Dev. (\%) & & 0.04 & 0.00 & 0.09 \\
\hline Test data & $25-30$ & 101.06 & 100.86 & 100.76 \\
\hline Calibr. data & $31-36$ & 100.98 & 100.93 & 101.15 \\
\hline Dev. (\%) & & 0.08 & 0.07 & 0.39 \\
\hline Test data & $37-42$ & 101.27 & 100.99 & 101.23 \\
\hline Calibr. data & $43-48$ & 101.11 & 100.90 & 101.09 \\
\hline Dev. (\%) & & 0.16 & 0.08 & 0.14 \\
\hline Test data & $49-54$ & 51.71 & 51.35 & 51.68 \\
\hline Calibr. data & $55-60$ & 51.56 & 51.34 & 51.56 \\
\hline Dev. $(\%)$ & & 0.29 & 0.02 & 0.24 \\
\hline Test data & $61-66$ & 51.19 & 51.00 & 51.22 \\
\hline Calibr. data & $67-72$ & 51.29 & 51.07 & 51.25 \\
\hline Dev. (\%) & & 0.19 & 0.13 & 0.07 \\
\hline Test data & $73-78$ & 151.00 & 150.84 & 151.06 \\
\hline Calibr. data & $79-84$ & 151.00 & 150.8 & 150.97 \\
\hline Dev. (\%) & & 0.00 & 0.02 & 0.06 \\
\hline Test data & $85-90$ & 101.10 & 100.89 & 101.11 \\
\hline Calibr. data & $91-96$ & 101.06 & 100.80 & 101.11 \\
\hline Dev. $(\%)$ & & 0.04 & 0.09 & 0.00 \\
\hline Test data & $97-102$ & 51.33 & 51.27 & 51.46 \\
\hline Calibr. data & $103-108$ & 51.33 & 51.27 & 51.59 \\
\hline Dev. $(\%)$ & & 0.00 & 0.01 & 0.24 \\
\hline \multicolumn{5}{|l|}{$T_{2}$} \\
\hline Test data & $1-6$ & 151.42 & 151.14 & 151.51 \\
\hline Calibr. data & $7-12$ & 151.26 & 151.11 & 151.36 \\
\hline Dev. (\%) & & 0.11 & 0.02 & 0.10 \\
\hline Test data & $13-18$ & 151.47 & 151.14 & 151.44 \\
\hline Calibr. data & $19-24$ & 151.45 & 151.10 & 151.53 \\
\hline Dev. $(\%)$ & & 0.01 & 0.03 & 0.06 \\
\hline Test data & $25-30$ & 101.08 & 100.79 & 101.24 \\
\hline Calibr. data & $31-36$ & 101.35 & 100.84 & 101.36 \\
\hline Dev. (\%) & & 0.27 & 0.06 & 0.12 \\
\hline Test data & $37-42$ & 101.17 & 100.88 & 101.11 \\
\hline Calibr. data & $43-48$ & 101.25 & 100.97 & 101.18 \\
\hline Dev. (\%) & & 0.08 & 0.09 & 0.07 \\
\hline Test data & $49-54$ & 51.55 & 51.11 & 51.45 \\
\hline Calibr. data & $55-60$ & 51.56 & 51.17 & 51.45 \\
\hline Dev. $(\%)$ & & 0.03 & 0.12 & 0.01 \\
\hline Test data & $61-66$ & 51.06 & 50.83 & 51.03 \\
\hline Calibr. data & $67-72$ & 51.15 & 50.79 & 51.01 \\
\hline
\end{tabular}


Table 11 continued

\begin{tabular}{lcrrr}
\hline $\mathrm{T}_{1}$ & Specimen $\mathrm{nr}$ & $\mathrm{b}_{1 \mathrm{f}}(\mathrm{mm})$ & $\mathrm{b}_{1 \mathrm{~m}}(\mathrm{~mm})$ & $\mathrm{b}_{1 \mathrm{e}}(\mathrm{mm})$ \\
\hline Dev. (\%) & & 0.17 & 0.07 & 0.03 \\
Test data & $73-78$ & 151.54 & 151.14 & 151.53 \\
Calibr. data & $79-84$ & 151.50 & 151.10 & 151.46 \\
Dev. (\%) & & 0.03 & 0.03 & 0.05 \\
Test data & $85-90$ & 101.18 & 100.85 & 101.07 \\
Calibr. data & $91-96$ & 101.28 & 100.95 & 101.16 \\
Dev. (\%) & & 0.11 & 0.10 & 0.09 \\
Test data & $97-102$ & 51.70 & 51.25 & 51.65 \\
Calibr. data & $103-108$ & 51.88 & 51.37 & 51.68 \\
Dev. (\%) & & 0.36 & 0.24 & 0.05 \\
\hline
\end{tabular}

Table 12 Standard deviation of widths for T1 and T2 according to Table 11

\begin{tabular}{llll}
\hline Test series & $\operatorname{Dev}\left(\mathrm{b}_{1 \mathrm{f}}\right)(\mathrm{mm})$ & $\operatorname{Dev}\left(\mathrm{b}_{1 \mathrm{~m}}\right)(\mathrm{mm})$ & $\operatorname{Dev}\left(\mathrm{b}_{1 \mathrm{e}}\right)(\mathrm{mm})$ \\
\hline$T_{1}$ & & & \\
$\mathrm{~B}_{1}$ & 0.17 & 0.16 & 0.22 \\
$\mathrm{~B}_{2}$ & 0.22 & 0.14 & 0.25 \\
$\mathrm{~B}_{3}$ & 0.23 & 0.19 & 0.23 \\
$T_{2}$ & & & \\
$\mathrm{~B}_{1}$ & 0.14 & 0.13 & 0.15 \\
$\mathrm{~B}_{2}$ & 0.14 & 0.12 & 0.27 \\
$\mathrm{~B}_{3}$ & 0.31 & 0.26 & 0.29 \\
$\mathrm{~B}_{4}$ & 0.22 & 0.14 & 0.30 \\
$\mathrm{~B}_{5}$ & 0.15 & 0.15 & 0.09 \\
$\operatorname{Dev}\left(T_{1} / T_{2}\right)$ & & & \\
$\mathrm{B}_{1}$ & 0.26 & 0.20 & 0.28 \\
$\mathrm{~B}_{2}$ & 0.19 & 0.13 & 0.26 \\
$\mathrm{~B}_{3}$ & 0.28 & 0.24 & 0.26 \\
\hline
\end{tabular}

train curves with $0^{\circ}, 45^{\circ}$ and $90^{\circ}$ to the rolling direction for $\mathrm{B}_{1}$ and $\mathrm{B}_{2}$. For $\mathrm{B}_{3}$, only $0^{\circ}$ specimens could be realized with scientific validity. It is important to note that the resulting $\mathrm{h}_{1}$ of each specimen varies as the final $\mathrm{s}_{0}$ was kept constant but the resulting cumulated force diverges significantly and therefore, the elastic spring back behavior as well as work hardening and force related heat expansion of the used Aluminum alloy contributes to the final thickness to different extends (Fig. 19). Table 13 shows the initial properties of each specimen used for additional tensile tests. For each sheet, three tensile tests specimens for each examined direction were produced, one sheet per corresponding test data series for $T_{1}$ and $T_{2}$. Figure 19 shows the normed specimen geometry, according to DIN EN 10002-1 (German Institute for Standardization), for the performed tensile tests.

The higher deviation in the cross section is a result of the sample production, which were cut out with a water jet cutter at the CMF. More important, it can be stated that the resulting
DIN EN 10002-1

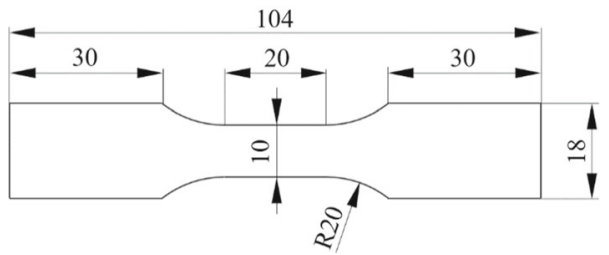

Fig. 19 Tensile test: initial geometry (German Institute for Standardization)

Table 13 Statistical comparison of $\mathrm{h}_{1}$ and resulting cross section for all tensile test specimens according to the initial rolling schedule

\begin{tabular}{lllll}
\hline $\begin{array}{l}\text { Specimen } \\
\text { nr./schedule }\end{array}$ & Test series & $\begin{array}{l}\text { Initial width } \\
(\mathrm{mm})\end{array}$ & $\begin{array}{l}\text { Thickness } \mathrm{h}_{1} \\
(\mathrm{~mm})\end{array}$ & $\begin{array}{l}\text { Cross } \\
\text { section } \\
\left(\mathrm{mm}^{2}\right)\end{array}$ \\
\hline $2 / \mathrm{V}_{2}$ & $\mathrm{~T}_{1}$ & $\mathrm{~B}_{1}$ & $1.34 \pm 0.01$ & $13.52 \pm 0.12$ \\
$2 / \mathrm{V}_{2}$ & $\mathrm{~T}_{2}$ & $\mathrm{~B}_{1}$ & $1.50 \pm 0.01$ & $15.25 \pm 0.15$ \\
$14 / \mathrm{V}_{3}$ & $\mathrm{~T}_{1}$ & $\mathrm{~B}_{1}$ & $1.33 \pm 0.01$ & $13.39 \pm 0.09$ \\
$14 / \mathrm{V}_{3}$ & $\mathrm{~T}_{2}$ & $\mathrm{~B}_{1}$ & $1.46 \pm 0.01$ & $14.82 \pm 0.13$ \\
$26 / \mathrm{V}_{2}$ & $\mathrm{~T}_{1}$ & $\mathrm{~B}_{2}$ & $1.20 \pm 0.01$ & $12.10 \pm 0.10$ \\
$26 / \mathrm{V}_{2}$ & $\mathrm{~T}_{2}$ & $\mathrm{~B}_{2}$ & $1.37 \pm 0.01$ & $13.89 \pm 0.21$ \\
$38 / \mathrm{V}_{3}$ & $\mathrm{~T}_{1}$ & $\mathrm{~B}_{2}$ & $1.20 \pm 0.01$ & $12.14 \pm 0.18$ \\
$38 / \mathrm{V}_{3}$ & $\mathrm{~T}_{2}$ & $\mathrm{~B}_{2}$ & $1.35 \pm 0.01$ & $13.56 \pm 0.16$ \\
$50 / \mathrm{V}_{2}$ & $\mathrm{~T}_{1}$ & $\mathrm{~B}_{3}$ & $1.01 \pm 0.00$ & $10.23 \pm 0.06$ \\
$50 / \mathrm{V}_{2}$ & $\mathrm{~T}_{2}$ & $\mathrm{~B}_{3}$ & $1.17 \pm 0.00$ & $11.87 \pm 0.04$ \\
$62 / \mathrm{V}_{3}$ & $\mathrm{~T}_{1}$ & $\mathrm{~B}_{3}$ & $1.01 \pm 0.01$ & $10.24 \pm 0.10$ \\
$62 / \mathrm{V}_{3}$ & $\mathrm{~T}_{2}$ & $\mathrm{~B}_{3}$ & $1.13 \pm 0.00$ & $11.41 \pm 0.02$ \\
$74 / \mathrm{V}_{1}$ & $\mathrm{~T}_{1}$ & $\mathrm{~B}_{1}$ & $1.22 \pm 0.00$ & $12.30 \pm 0.12$ \\
$74 / \mathrm{V}_{1}$ & $\mathrm{~T}_{2}$ & $\mathrm{~B}_{1}$ & $1.33 \pm 0.01$ & $13.33 \pm 0.13$ \\
$86 / \mathrm{V}_{1}$ & $\mathrm{~T}_{1}$ & $\mathrm{~B}_{2}$ & $1.10 \pm 0.00$ & $11.05 \pm 0.11$ \\
$86 / \mathrm{V}_{1}$ & $\mathrm{~T}_{2}$ & $\mathrm{~B}_{2}$ & $1.21 \pm 0.01$ & $12.14 \pm 0.20$ \\
$98 / \mathrm{V}_{1}$ & $\mathrm{~T}_{1}$ & $\mathrm{~B}_{3}$ & $0.95 \pm 0.01$ & $9.58 \pm 0.16$ \\
$98 / \mathrm{V}_{1}$ & $\mathrm{~T}_{2}$ & $\mathrm{~B}_{3}$ & $1.03 \pm 0.00$ & $10.34 \pm 0.03$ \\
\hline
\end{tabular}

$\mathrm{h}_{1}$ for sheets that undergo the same treatment, except friction state $\left(T_{1}, T_{2}\right)$ vary significantly. For each state, the height of rolled sheets without lubrication is effectively higher than with. As a result of the higher $F_{R}$ applied, the sum of elastic suspension of stand parts involved in the force flow during the rolling process is significantly higher. Therefore, the same degree of forming is not achieved as with the $T_{1}$ series, and the plate thickness of the $T_{2}$ series does not reach the same $h_{1}$ as that with lubrication, especially when large height reductions within the process were set. Figures 20 and 21 show the comparison of a specimen with $\mathrm{B}_{1}$ (Fig. 20) and $\mathrm{B}_{2}$ (Fig. 21) for both friction states. A small but reproducible effect on strength due to anisotropy can be observed.

To investigate the influence of friction, the following Figs. 22, 23, 24 show the direct comparison between a specific rolling direction and both investigated test series. Figure 22 compares different tensile test specimens for $0^{\circ}$, $45^{\circ}$ and $90^{\circ}$ to rolling direction, for specimen nr. $14\left(\mathrm{~B}_{1}\right)$. The same comparison was made in Fig. 23 for specimen nr. 

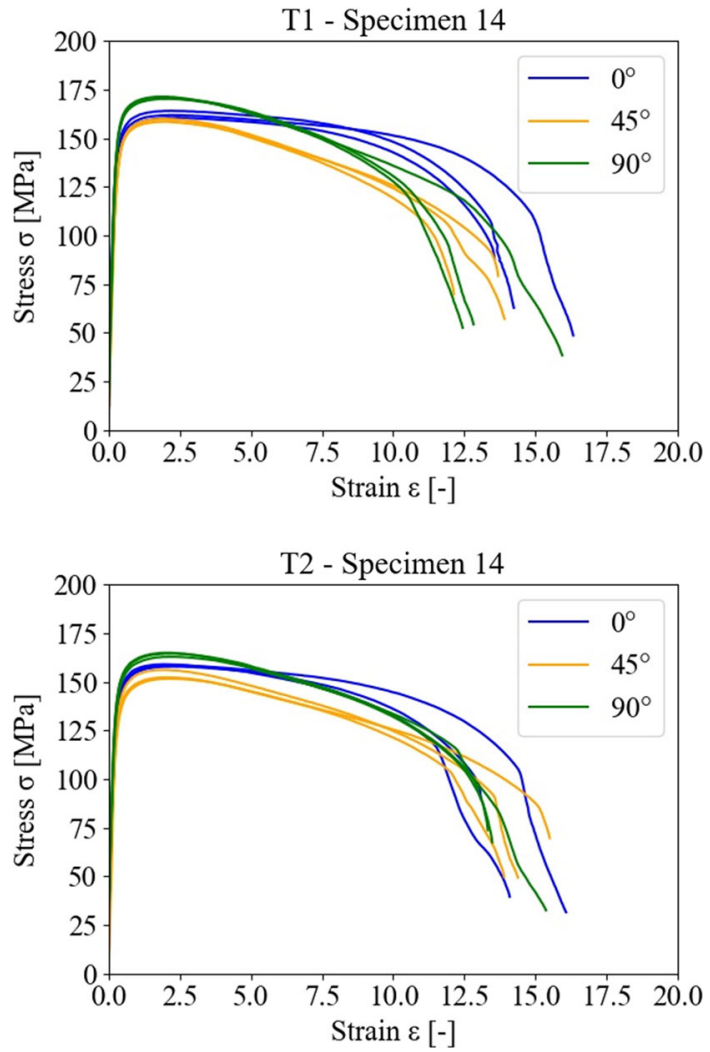

Fig. 20 Specimen nr. 14: mechanical anisotropy T1/T2

$86\left(\mathrm{~B}_{2}\right)$. In Fig. 24, the smallest width within the test and calibration series (specimen nr. 98, $\mathrm{B}_{3}$ ) is compared in rolling direction.

The initial strip is commonly produced by hot rolling. This treatment already elongates the grains in the rolling direction, therefore the grains align themselves along a preferred orientation. The resulting microstructure exhibits a so-called rolling texture, as visualized in Fig. 25. The resulting anisotropy of the grain orientation also commonly affects the mechanical properties. The considerably larger number of grain boundaries to be overcome $90^{\circ}$ to the rolling direction generally leads to an obstruction of the sliding processes. To determine the extent of anisotropy on sheet materials, tensile specimens are therefore regularly extracted and tested at $0^{\circ}$, $45^{\circ}$ and $90^{\circ}$ to the rolling direction. The recovery discussed in Sect. 6.2, however, leads to another phenomenon that is essential in explaining the low influence of anisotropy on macromechanical properties (Figs. 20 and 21), namely the polygonization of small-angle grain boundaries. This effect results in a substructure that forms globular sub grains. In optical microscopy images (OMI), this rearrangement is difficult to detect. In this case, the Barker electrolytic etching was used to visualize the microstructure (Figs. 25, 26, 27 , 28 ), only showing the superposed deformation structure. It can be assumed that the progressed recovery stage in the
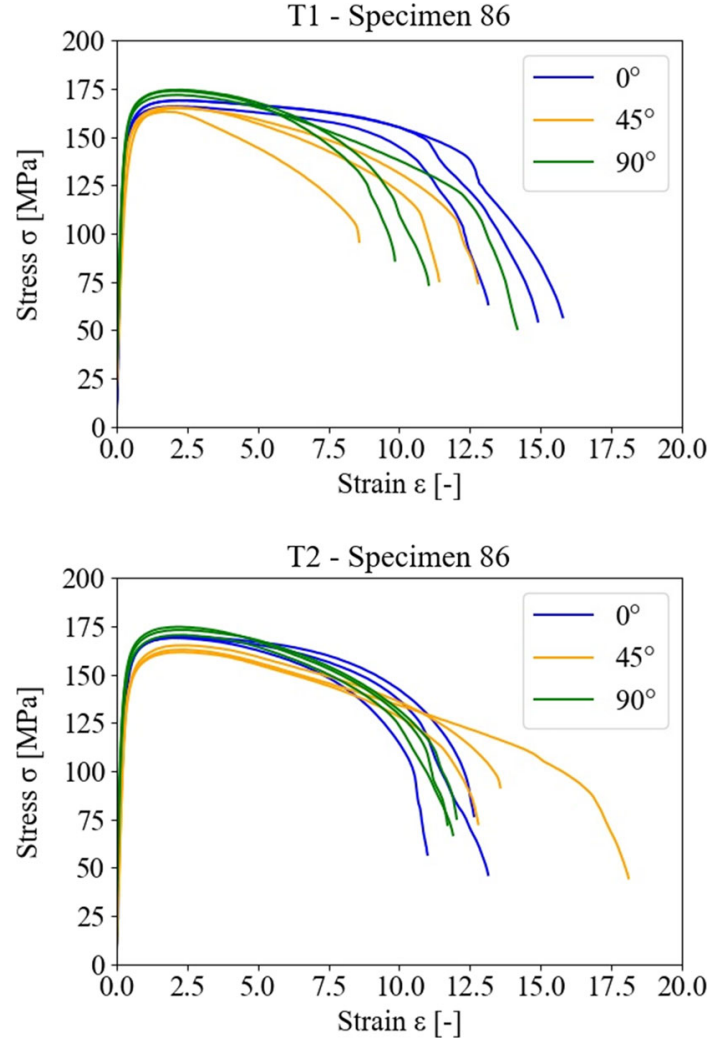

Fig. 21 Specimen nr. 86: mechanical anisotropy T1/T2

pure aluminum used in this experimental setup is most likely responsible for the similar deformation properties between the directions in the tensile test (Humphreys \& Hatherly, 2007).

Table 14 summarizes the resulting ultimate tensile strength (UTS) of each tested specimen under consideration of tested degree to rolling direction.

The low but significant differences in UTS between different measured directions of one specimen can be explained as stated previously. The reproducible deviations in UTS between different specimens are a result of geometric differences, as specimens with different $h_{1}$ and therefore initial cross sections have different damage mechanisms dominating. The thinner the respective specimen, the more the plane stress state dominates, which results in higher resistance against damage and therefore slightly higher UTS values.

\section{Data based experimental results}

As stated in Sect. 6.4, the higher resulting friction within the tribological system of test series $\mathrm{T}_{2}$ result in a higher elastic suspension of the stand components of the rolling aggregate. This phenomenon leads to a higher increase of $h_{0}$ as well as $h_{1}$ in $T_{2}$ compared to $T_{1}$. Despite the resulting higher $h_{1}$, the rolling mill and especially the mill stand has to apply higher 

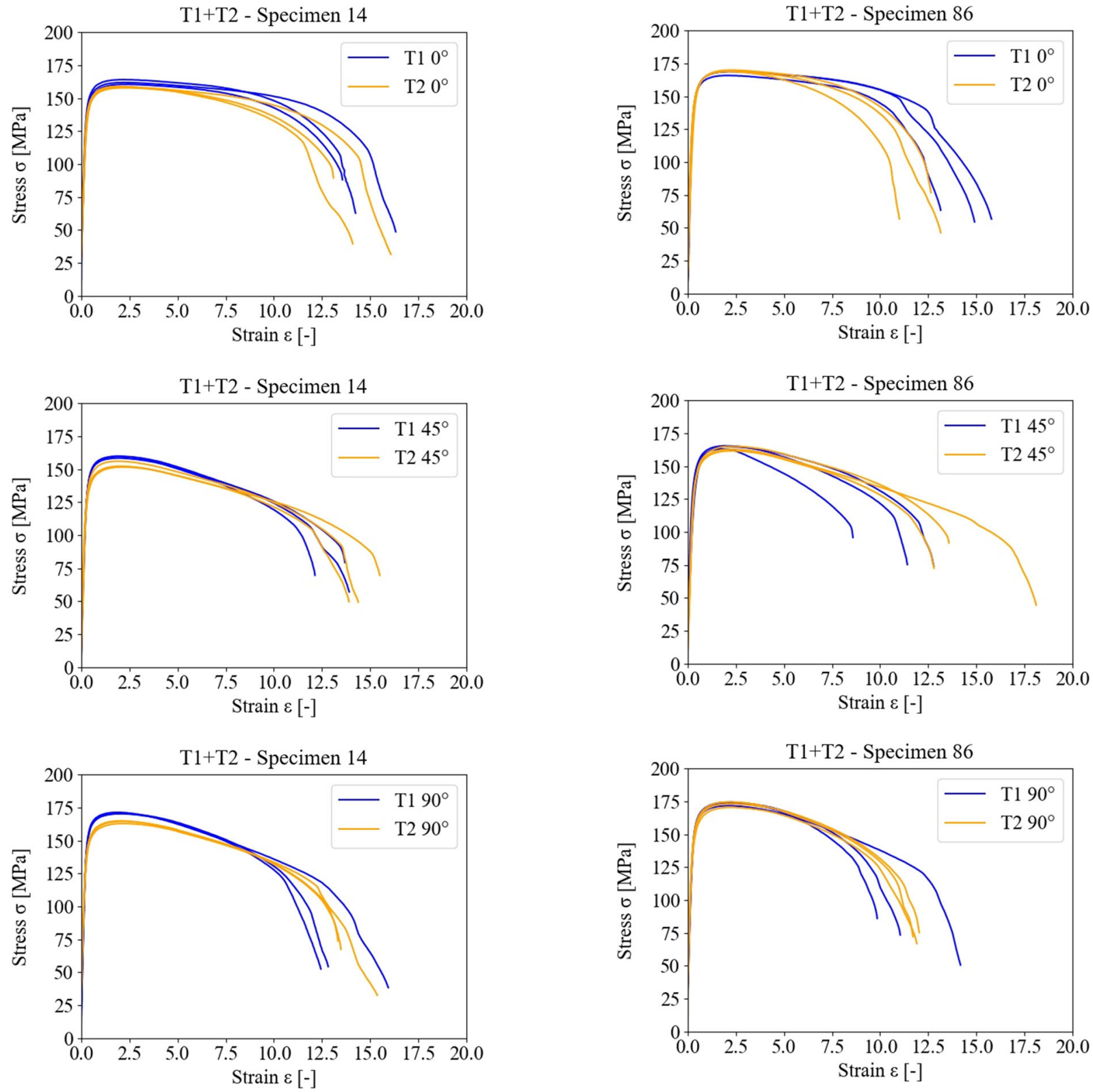

Fig. 22 Direct comparison: specimen nr. 14

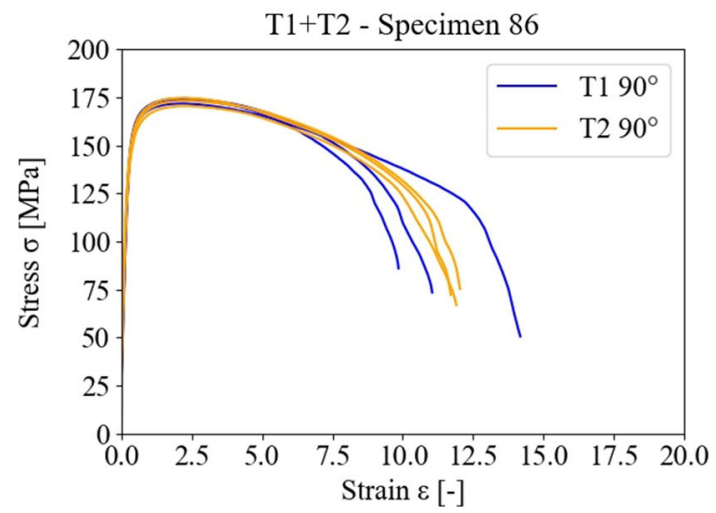

Fig. 23 Direct comparison: specimen nr. 86

forces than in the tribologic system with adequate lubrication. Figure 29 demonstrates this effect on the resulting $F_{R}$ on an exemplary rolling force hysteresis, where the same specimen from $T_{1}$ is compared with $T_{2}$. The effect of higher $F_{R}$ for $\mathrm{T}_{2}$ occurs in all different widths, as Figs. $30 \mathrm{~B}_{2}$ and $31 \mathrm{~B}_{3}$ demonstrate.

Figure 32 shows a direct comparison between $\mathrm{B}_{1}, \mathrm{~B}_{2}$ andB 3 from the same rolling schedule and $\mathrm{s}_{0}$, for $\mathrm{T}_{1}$ (Fig. 32, top) and $\mathrm{T}_{2}$ (Fig. 32, bottom).

The unnatural angular curve progression is a result of the sample rate during rolling $(500 \mathrm{~Hz})$. To obtain smoother results, a controlling unit (Sect. 4.2, Fig. 10) capable of higher frequency would have to be implemented. As this plot only serves as a complementary visualization and the maximum valid sample rate is sufficient for the development of the machine learning algorithm (Sect. 6.6), the controlling unit is not changed within this case study.

For the development of the algorithm described in this paper, the maximum rolling force $F_{R}$ is of importance, whereas the curve progression is not relevant for the resulting digital twin. The usage of the maximum resulting force as $F_{R}$ can be seen as valid, as the deviation between this value and corresponding data points within the rolling process doesn't exceed $0.05 \%$. Figure 33 shows an exemplary $F_{R}$ (time) curve from a rolling process carried out. 


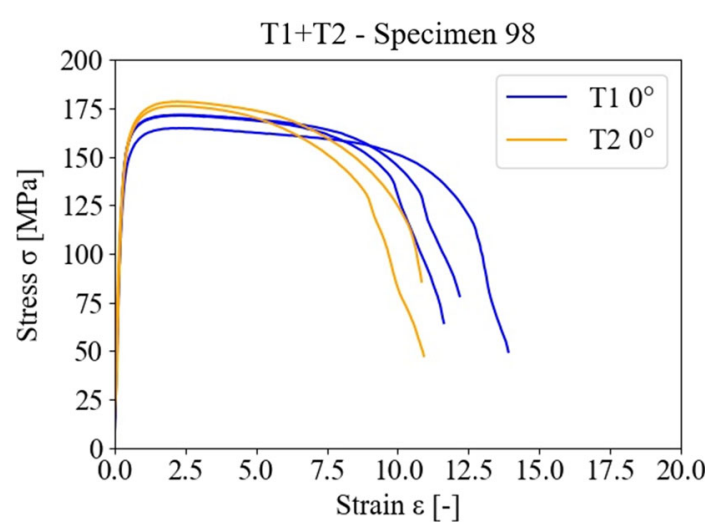

Fig. 24 Direct comparison: specimen nr. 98

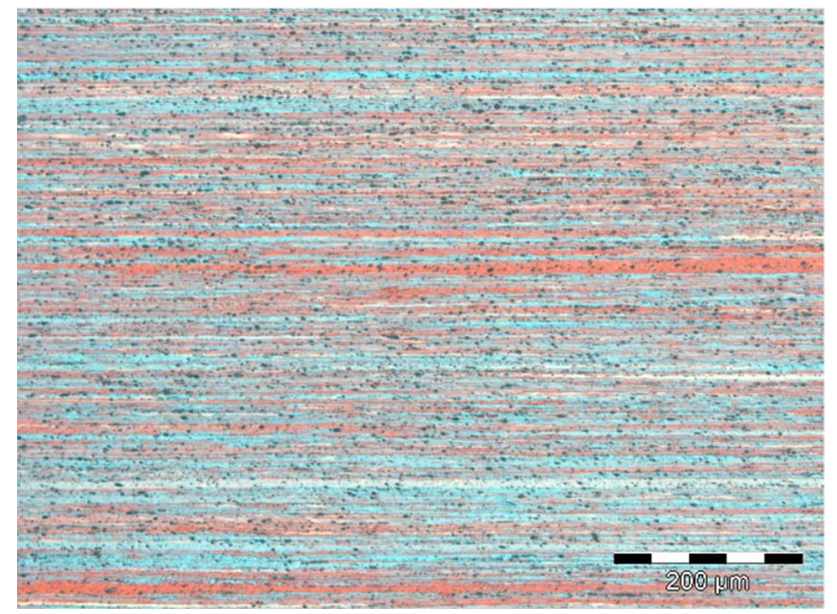

Fig. 25 Exemplary OMI: initial microstructure in rolling direction $\left(\mathrm{T}_{1}\right.$ /specimen $\mathrm{nr} .86,0^{\circ}$ )

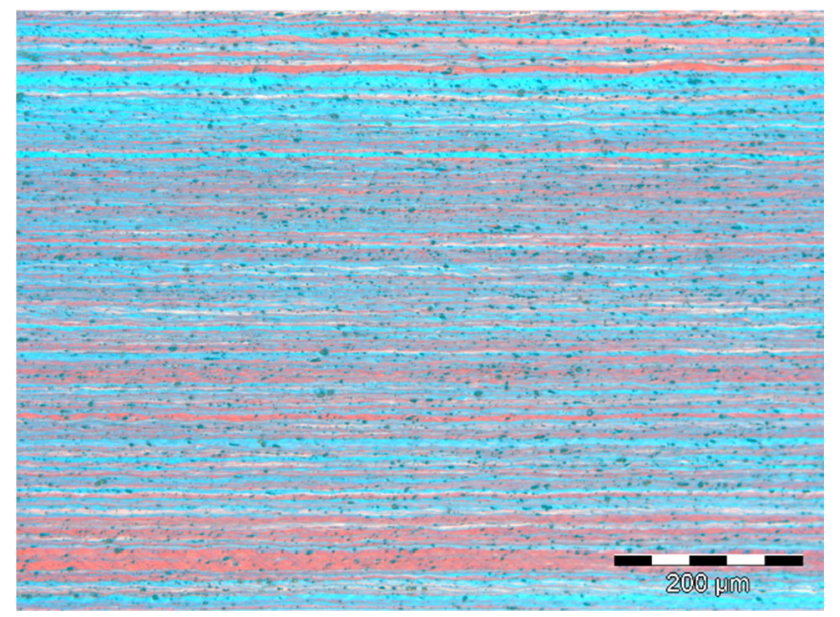

Fig. 26 Exemplary OMI: microstructure after the rolling process $\left(\mathrm{T}_{1}\right.$ /specimen nr. $86,0^{\circ}$ )

Figure 34 shows the resulting data points for each process step within the test and calibration data setup, divided in test series and initial widths. In this diagram, a clear correlation

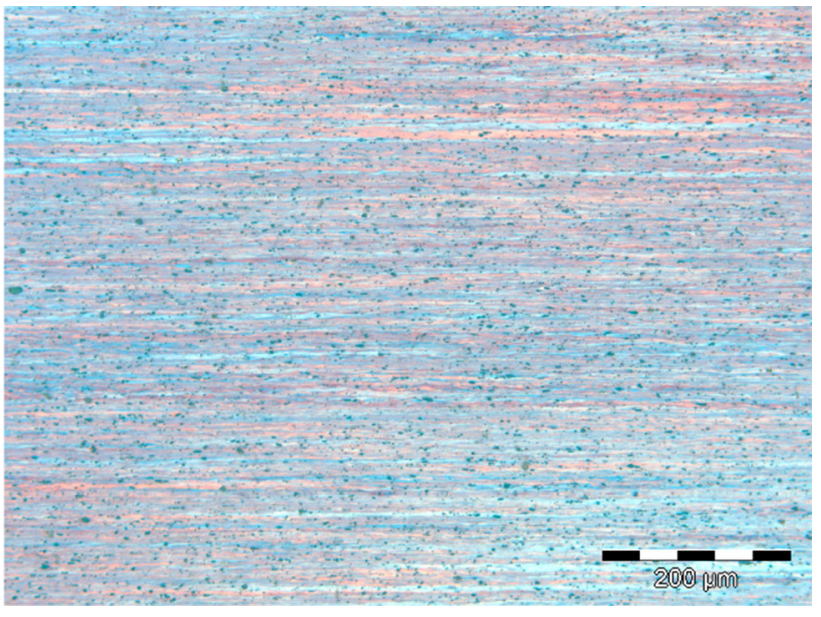

Fig. 27 Exemplary OMI: microstructure after the rolling process $\left(\mathrm{T}_{1}\right.$ /specimen nr. $86,45^{\circ}$ )

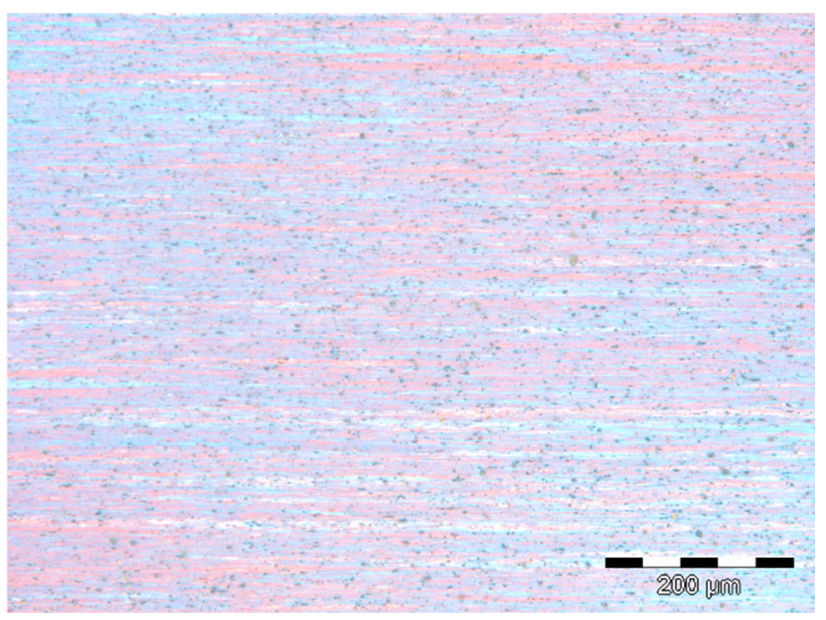

Fig. 28 Exemplary OMI: microstructure after the rolling process $\left(\mathrm{T}_{1}\right.$ /specimen nr. $86,90^{\circ}$ )

between $F_{R}, \Delta h\left(s_{0}\right), B_{i}$ and $T_{i}$ can be identified. As expected, test and validation data points for the same $\mathrm{B}, \mathrm{V}$ and $\mathrm{T}$ cannot be separated. Therefore, no difference between those sets will be made in the following visualizations.

As described in Sect. 6.4, a difference between the maximum roll gap (s) and the resulting $\mathrm{h}_{1}$ of a specimen occurs. This effect can be demonstrated by plotting the same data points as a function of the maximum s (Figs. 35 and 36, yellow surface) and $h_{1}$ (Figs. 35 and 36, blue surface). As visualized in Fig. 34, the difference between $\mathrm{T}_{1}$ (Fig. 35) and $\mathrm{T}_{2}$ (Fig. 36) can be seen due the offset of data points to higher $F_{R}$ with $T_{2}$. The dependencies described in Eq. (6) (Sect. 6.1) and the effect of cold working (Sect. 6.2) result in higher rolling forces with increasing $\Delta \mathrm{h}$ and decreasing $\mathrm{s}_{0}$. As expected, the difference in the tribological system results in significantly higher $F_{R}$ in $T_{2}$ in comparison to $T_{1}$. Also, higher $F_{R}$ correlates with increasing initial sheet width. These 
Table 14 Statistical comparison of UTS for tensile test specimens according to the initial rolling schedule

\begin{tabular}{|c|c|c|c|}
\hline Nr./test series & $\begin{array}{l}\operatorname{UTS}\left(0^{\circ}\right) \\
(\mathrm{MPa})\end{array}$ & $\begin{array}{l}\mathrm{UTS}\left(45^{\circ}\right) \\
(\mathrm{MPa})\end{array}$ & $\begin{array}{l}\mathrm{UTS}\left(90^{\circ}\right) \\
(\mathrm{MPa})\end{array}$ \\
\hline $2 / \mathrm{T}_{1}$ & $166.54 \pm 1.82$ & $160.98 \pm 0.86$ & $171.27 \pm 1.23$ \\
\hline $2 / \mathrm{T}_{2}$ & $162.35 \pm 1.26$ & $156.40 \pm 0.46$ & $164.10 \pm 1.46$ \\
\hline $14 / \mathrm{T}_{1}$ & $162.21 \pm 1.48$ & $159.41 \pm 0.64$ & $170.82 \pm 0.45$ \\
\hline $14 / T_{2}$ & $158.53 \pm 0.45$ & $153.37 \pm 1.97$ & $164.18 \pm 0.87$ \\
\hline $26 / T_{1}$ & $165.22 \pm 1.28$ & $162.41 \pm 1.26$ & $172.05 \pm 0.56$ \\
\hline $26 / T_{2}$ & $163.94 \pm 1.28$ & $160.67 \pm 1.80$ & $167.75 \pm 1.24$ \\
\hline $38 / \mathrm{T}_{1}$ & $167.75 \pm 1.02$ & $160.28 \pm 1.22$ & $171.86 \pm 0.41$ \\
\hline $38 / \mathrm{T}_{2}$ & $162.29 \pm 1.68$ & $157.19 \pm 2.30$ & $167.47 \pm 1.04$ \\
\hline $50 / \mathrm{T}_{1}$ & $167.56 \pm 0.64$ & - & - \\
\hline $50 / \mathrm{T}_{2}$ & $170.85 \pm 1.11$ & - & - \\
\hline $62 / \mathrm{T}_{1}$ & $169.02 \pm 1.24$ & - & - \\
\hline $62 / T_{2}$ & $169.76 \pm 0.42$ & - & - \\
\hline $74 / T_{1}$ & $165.02 \pm 0.93$ & $163.23 \pm 0.53$ & $172.00 \pm 0.72$ \\
\hline $74 / T_{2}$ & $169.76 \pm 0.42$ & $156.65 \pm 2.08$ & $164.96 \pm 1.89$ \\
\hline $86 / \mathrm{T}_{1}$ & $167.95 \pm 1.45$ & $164.54 \pm 1.00$ & $173.38 \pm 1.13$ \\
\hline $86 / \mathrm{T}_{2}$ & $169.39 \pm 0.45$ & $163.29 \pm 1.43$ & $172.80 \pm 1.72$ \\
\hline $98 / \mathrm{T}_{1}$ & $169.32 \pm 2.15$ & - & - \\
\hline $98 / \mathrm{T}_{2}$ & $177.61 \pm 0.98$ & - & - \\
\hline
\end{tabular}

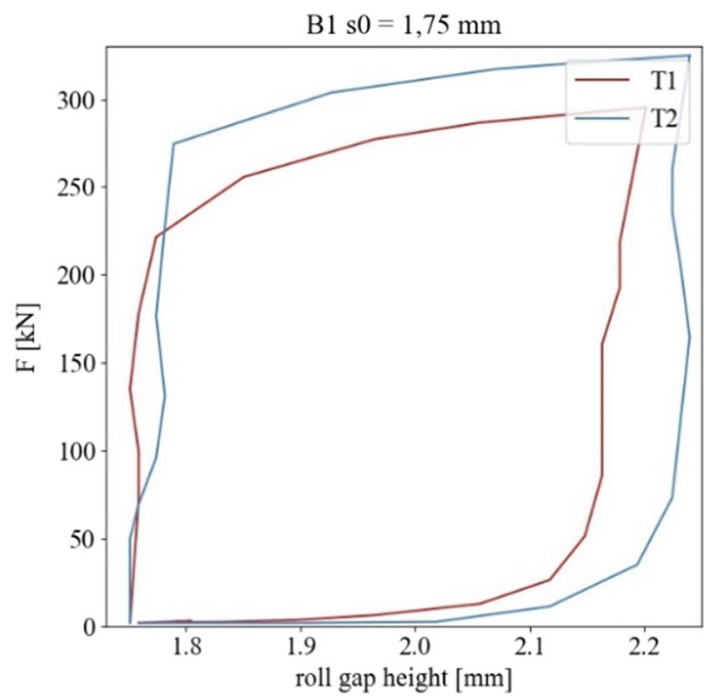

Fig. 29 Example of a rolling hysteresis: $\mathrm{B}_{1}$ for $\mathrm{s}_{0}=1.75 \mathrm{~mm}$

effects are cumulative, resulting in a maximum offset of $F_{R}$ between $\mathrm{B}_{1} / \mathrm{T}_{2}$ and $\mathrm{B}_{3} / \mathrm{T}_{1}$ at maximum value of the product $\Delta \mathrm{h}^{*} \mathrm{~s}_{0}$.

In order to validate the stated hypotheses regarding the correlation of introduced variables, the validation data were implemented into the $\mathrm{T}_{2}$ plane (Fig. 37). For a better visualization, only the $\mathrm{V}_{1}$ rolling schedule for each introduced $\mathrm{B}$ was plotted within. The resulting diagram shows a clear linear correlation between different widths and the corre-

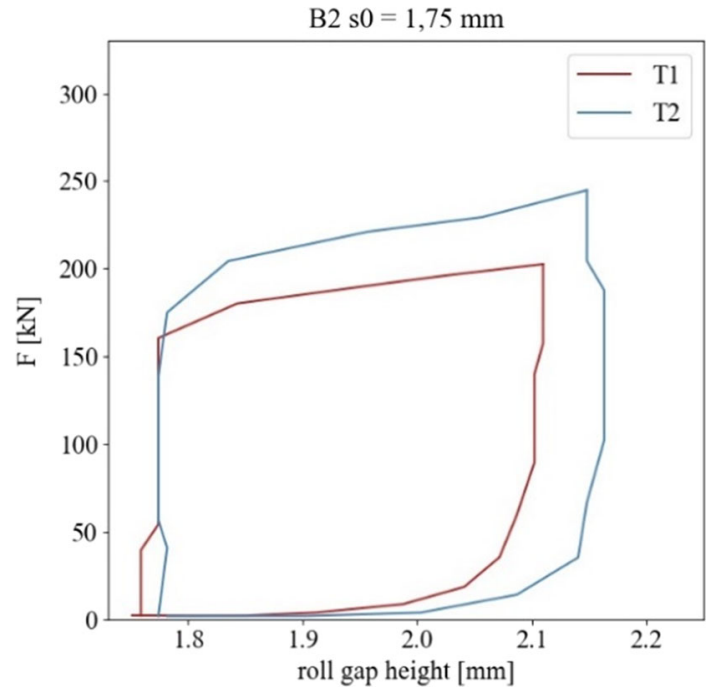

Fig. 30 Example of a rolling hysteresis: $\mathrm{B}_{2}$ for $\mathrm{s}_{0}=1.75 \mathrm{~mm}$

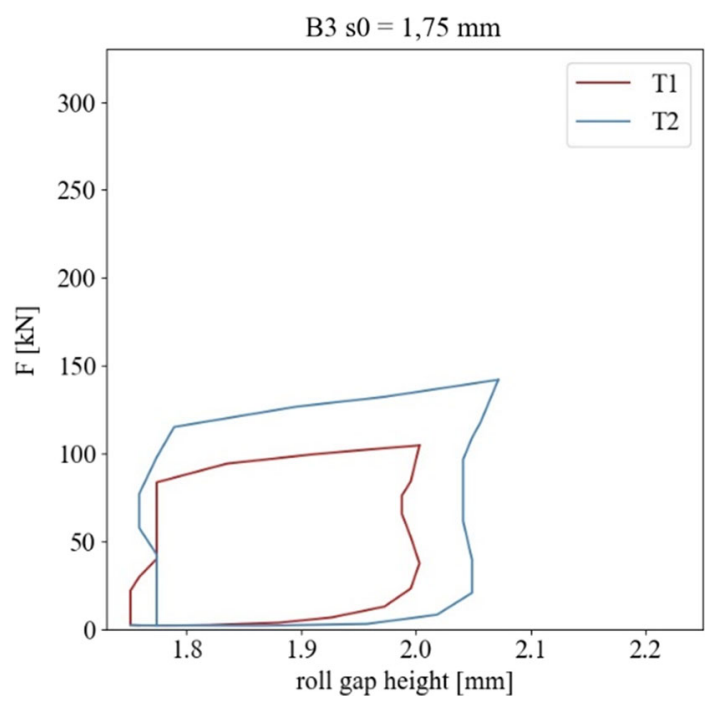

Fig. 31 Example of a rolling hysteresis: $\mathrm{B}_{3}$ for $\mathrm{s}_{0}=1.75 \mathrm{~mm}$

sponding $\mathrm{s}_{0}$ of $\mathrm{V}_{1}$. Furthermore, the modification of $\mathrm{V}_{1}$ at $\mathrm{s}_{0}=1.75 \mathrm{~mm}$ (with a following $\mathrm{s}_{0}$ of $0.75 \mathrm{~mm}$ instead of $1.00 \mathrm{~mm}$ ) also supports the correlations stated by the authors within this paper.

\section{Result based machine learning algorithm}

According to the statements made in the last subsections of Sect. 6, the developed machine learning algorithm operates on linear interpolation and extrapolation of given test, calibration and validation data (Fig. 38). The first setup is based on the logic demonstrated in Fig. 2, whereas the material curve was also modeled linear. For each given $F_{R}$ and corresponding $\mathrm{h}_{1}$, the algorithm interpolates with linear weighting functions between the initial data to obtain the working point 

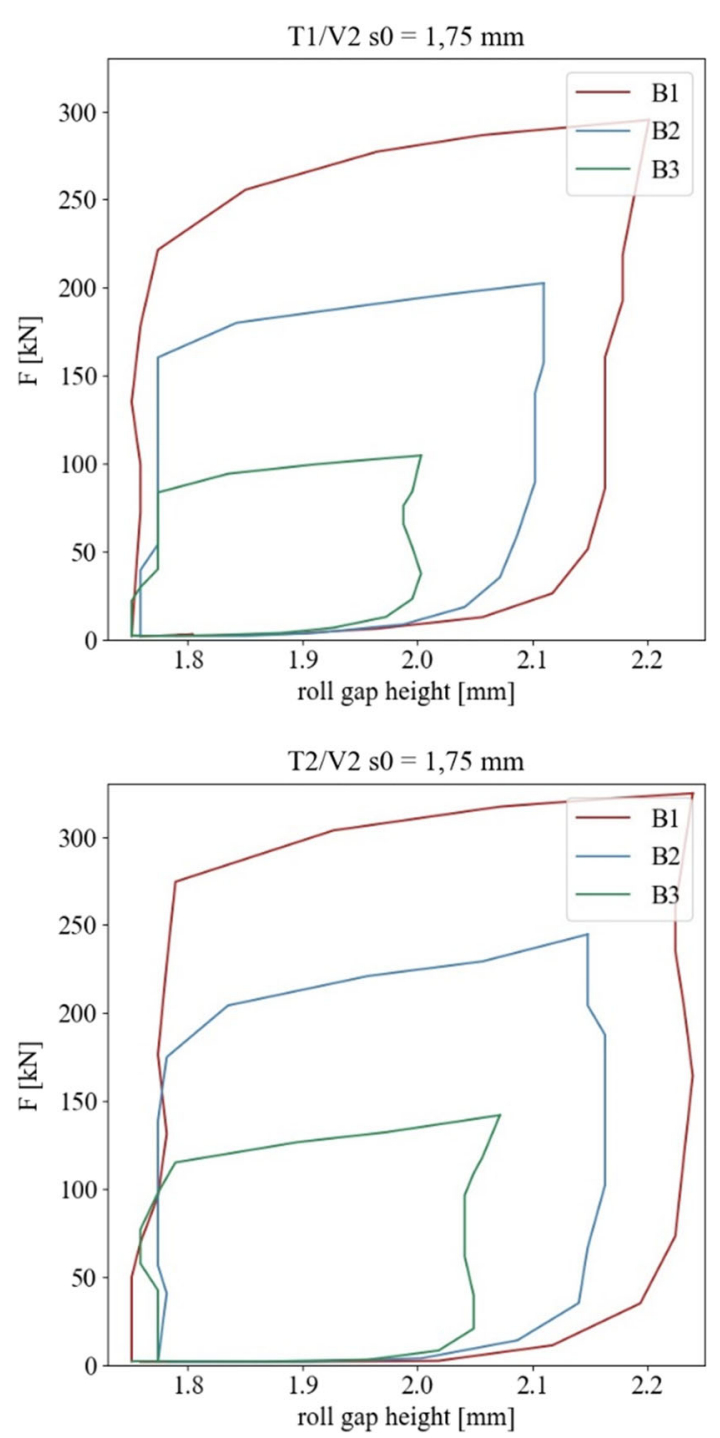

Fig. 32 Rolling hysteresis: resulting $F_{R}$ as a function of initial sheet width: comparison between $\mathrm{T}_{1}$ (top) and $\mathrm{T}_{2}$ (bottom)

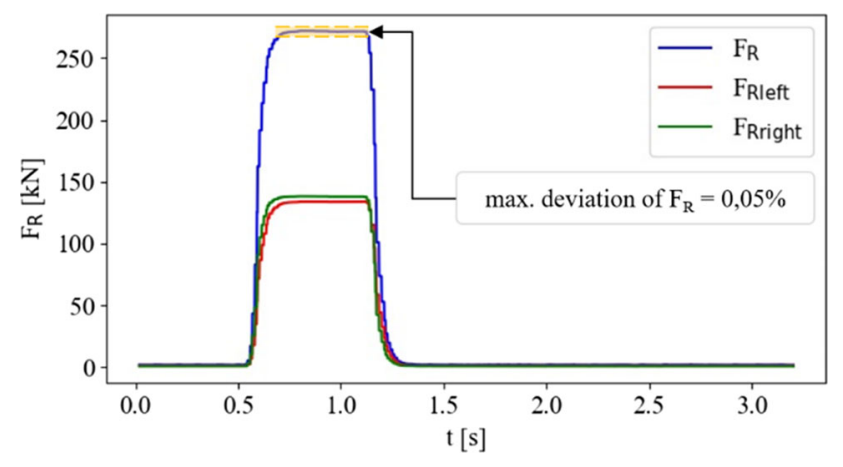

Fig. 33 Exemplary rolling force-time curve

A. This results in a new $h_{1}$, which is used as new input $h_{1}$ within a loop. As a result, a complete rolling schedule is obtained and in situ adapted during a carried out rolling pro-

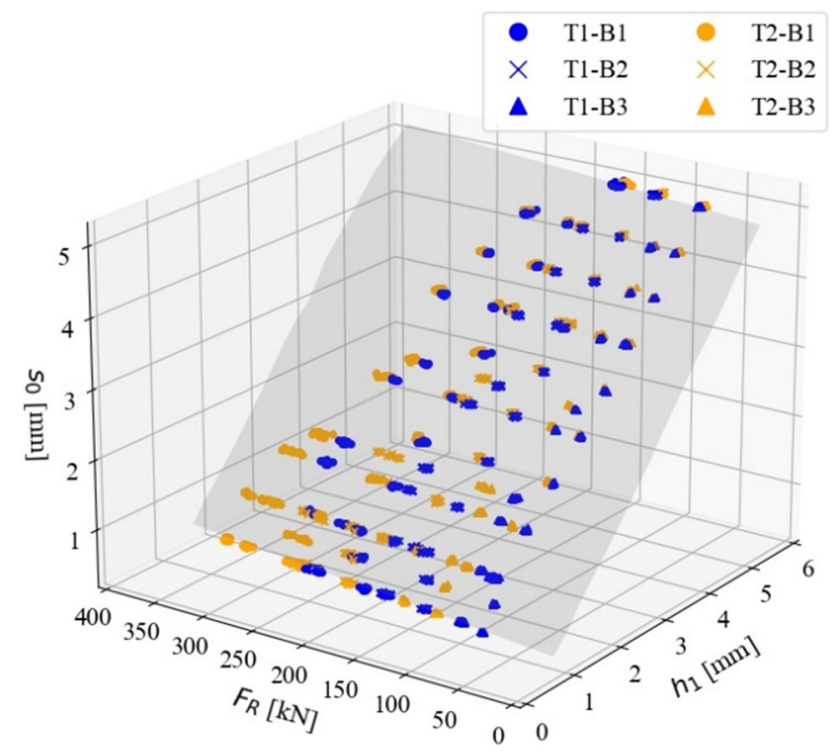

Fig. 34 Resulting data points (1736) from the test and calibration data series

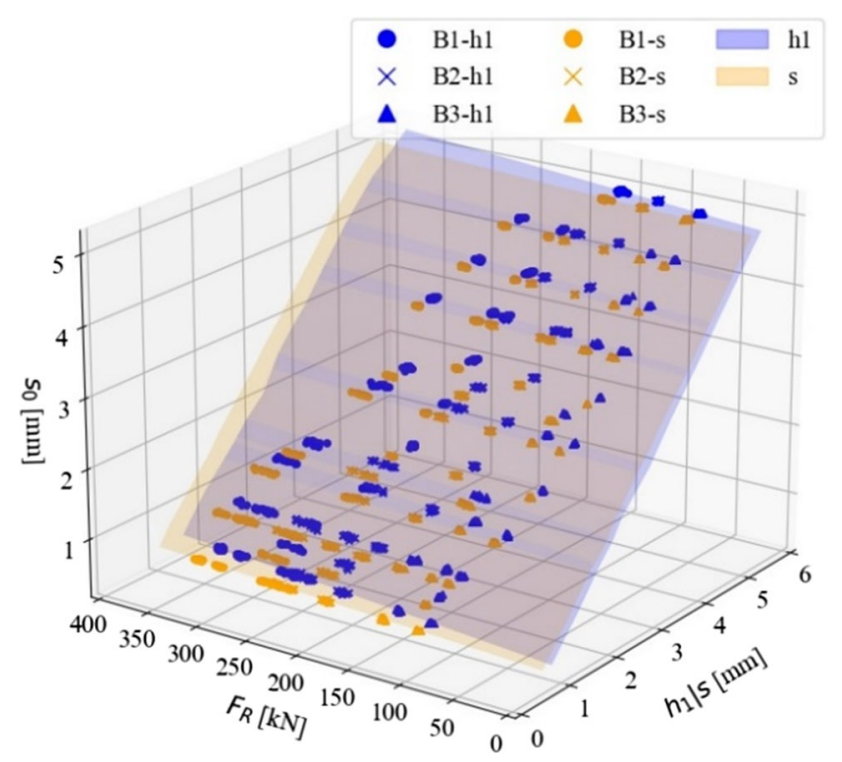

Fig. 35 Comparison between resulting $\mathrm{s}$ (yellow plane) and $\mathrm{h}_{1}$ (blue plane) for $\mathrm{B}_{1}, \mathrm{~B}_{2}$ and $\mathrm{B}_{3}$ within test series $\mathrm{T}_{1}$ (Color figure online)

cess. To develop this digital twin further and realize actual machine learning, final data of an executed rolling scheme is added to the respective initial data set $\left(\mathrm{T}_{1}\right.$ or $\left.\mathrm{T}_{2}\right)$ resulting in an overall adaption of the linearized functions for the characteristic rolling mill and material curve. Although it would be possible to use predefined machine learning algorithms (e.g. using the sci.py kit available within the Python environment), this logic has the advantage of a simple adaptability for other materials. Furthermore, it is easy to understand and adapt for learning students and other interested parties within the SFL at the Montanuniversität Leoben. 


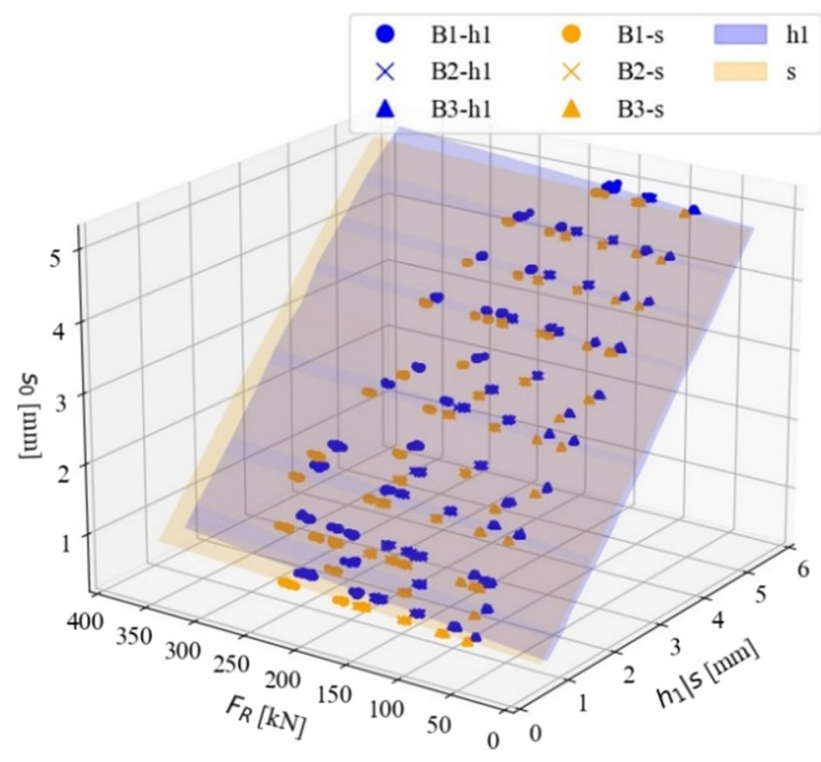

Fig. 36 Comparison between resulting $\mathrm{s}$ (yellow plane) and $\mathrm{h}_{1}$ (blue plane) for $\mathrm{B}_{1}, \mathrm{~B}_{2}$ and $\mathrm{B}_{3}$ within test series $\mathrm{T}_{2}$ (Color figure online)

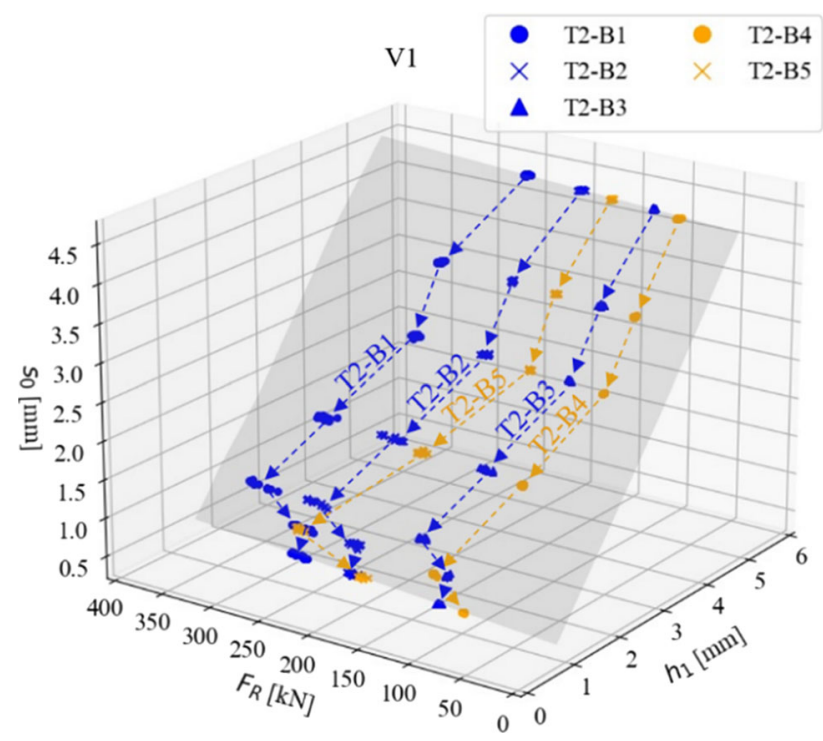

Fig. 37 Implementation of validation data: comparison with $\mathrm{V}_{1}$ of test and calibration data sets

\section{Machine learning GUI}

The logic visualized in Fig. 38 (Sect. 6.6) serves as a basis for the second front end GUI (Table 1, IV). This GUI is also developed using the open source version of Qt Creator. The corresponding code was programmed using $\mathrm{C}++$ and translated directly into Python within an appropriate translation framework (e.g. qtpy). As a result, the visualization can be started within the Python environment (e.g. using PyCharm or MS Visual Studio).
Figure 39 shows the resulting GUI for an exemplary rolling mill schedule. The possibility of including other materials is also considered.

The highlighted sequence (Fig. 39, green) indicates that no adaptions have been made and the generator calculated the complete scheme from the given input parameters (Fig. 39: Material, Rolling Force, $\mathrm{h}_{0}$, demanded final $\mathrm{h}_{1}$ after schedule, $\mathrm{T}_{1}$ or $\mathrm{T}_{2}$ ). After a rolling step, the real $\mathrm{h}_{1}$ can be measured on two points (Fig. 39, End height front end $h_{1}$, End height back end $\mathrm{h}_{1}$ ). Additionally, a change in width (according to Eq. (8), Sect. 6.3) or lubrication can be typed in, which also changes the result according to the fundamental logic (Fig. 38). Figure 40 demonstrates the influence of varying these parameters after a rolling step.

The user-given input parameters are triggering the machine logic. Furthermore, these parameters were also written into the initial database, which serves as fundament for the whole logic. Based on this data base extension, the logic is able to shift the boundaries for the extrapolation (if a B, $\mathrm{s}_{0}$ out of the initial widths is given) or generate new interpolation data points within the given boundaries. Regardless which condition is met, the algorithm changes its final interpolation logic by changing material and stand related slopes and intercepts. As this adaption is made via linear weighting functions between a small step increment, the influence on the change is rapidly decreasing with increasing distance from the generated data points. As the point cloud gets denser with every data input, the prediction gets more accurate with each rolling process carried out. Figure 41 shows an overview of this loop.

\section{Results and discussion}

For the development of a LC user centered CPPS, the chosen forming equipment, a rolling mill aggregate built in 1954, was digitized and digitalized from the implementation of state of the art sensor technology to the integration of a self-learning digital twin with corresponding GUI. For all necessary development steps, cost efficient but robust solutions were chosen, in order to be able to use this case study as a possible framework for SMEs and (academic) learning factories to develop CPPS based on similar technologies and in alignment with the initial definition stated by the authors in (2.2). Another focus within this paper, a wide and high usability for all interested parties of the developed solution was realized with two different front end and two easy to understand back end GUIs. The usage of LC and mostly open source software solutions is another advantage of this framework, as continuous updates are made in the open source community and expensive software maintenance is not necessary. Figure 42 shows the final data flow at the rolling mill, from analog sensor signals to the Python logic. 


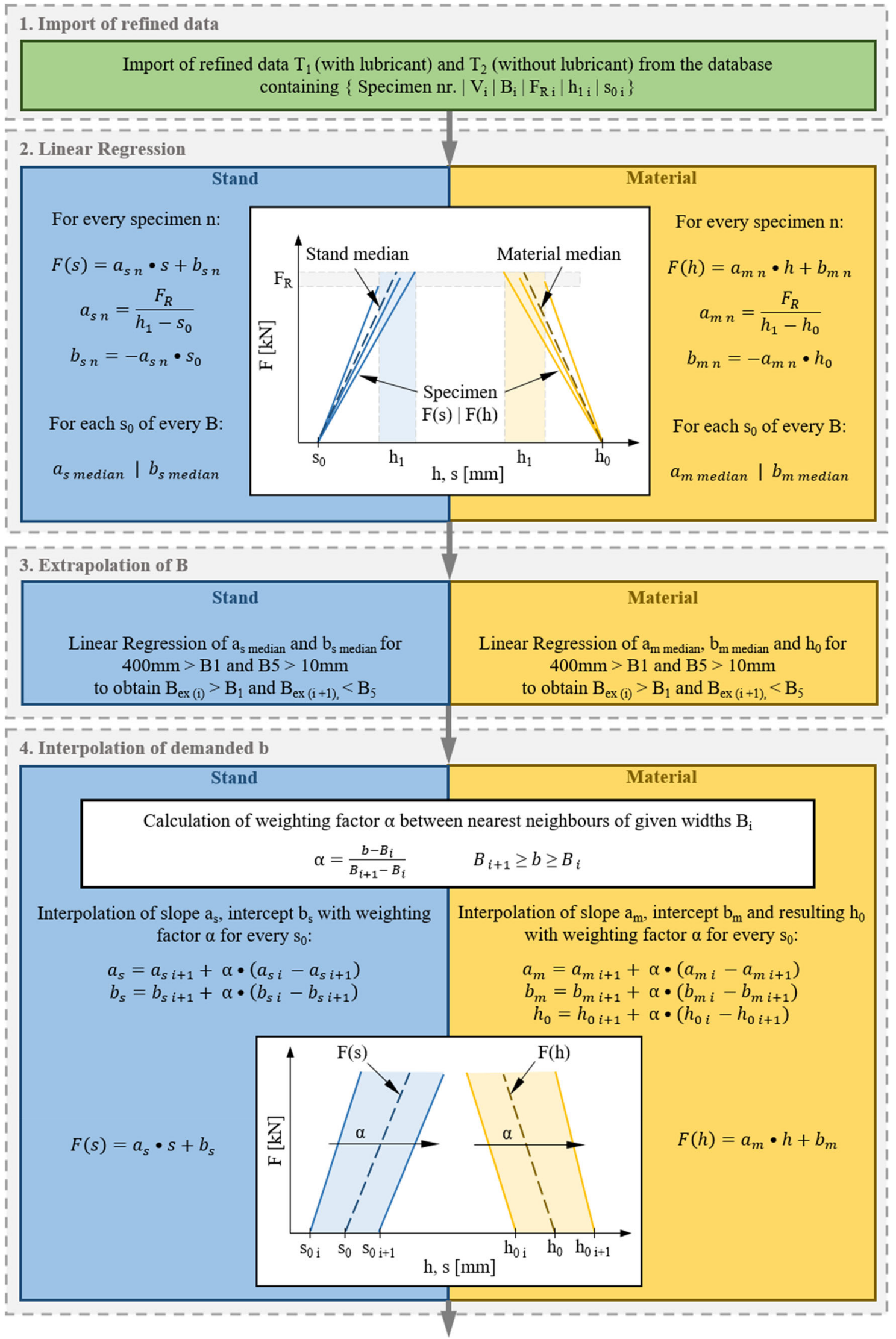

Fig. 38 Fundamental logic for the Python based rolling schedule iterator 


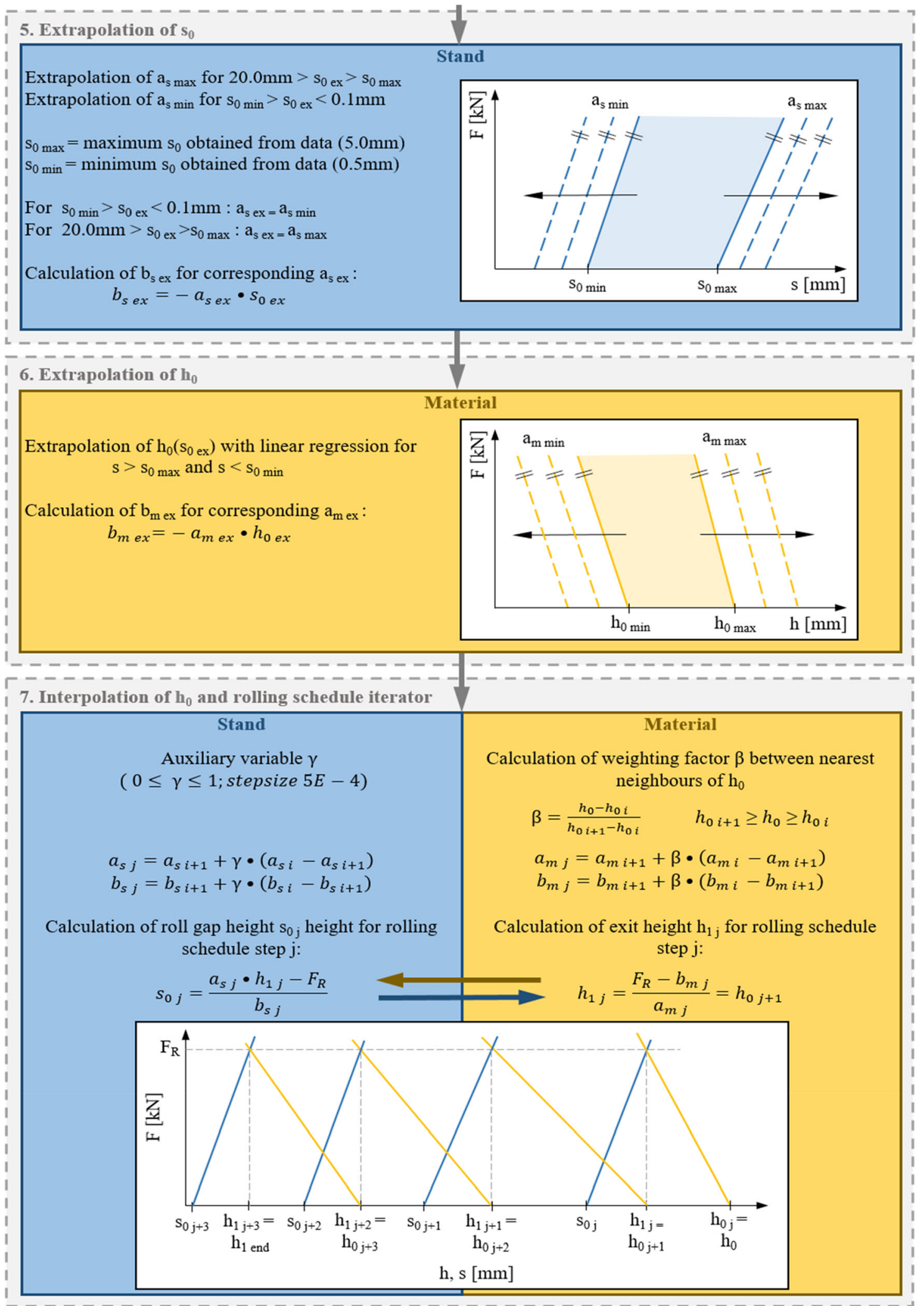

Fig. 38 continued 


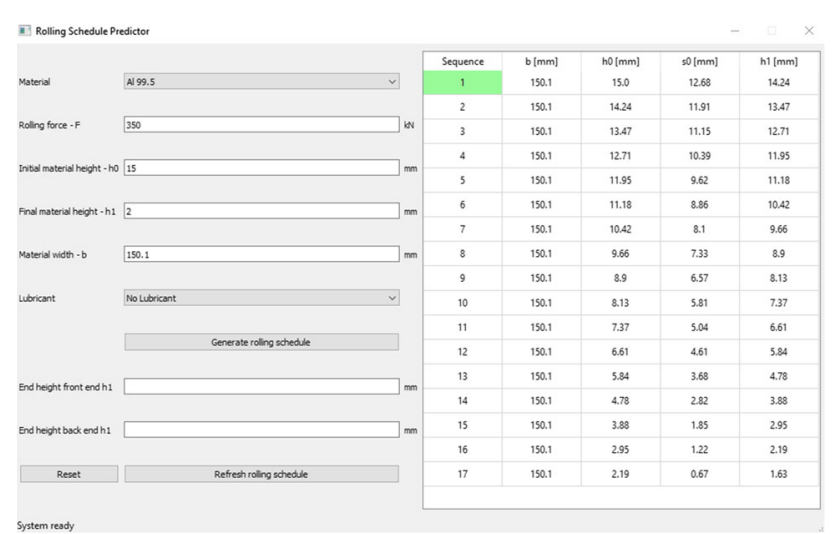

Fig. 39 Resulting front end GUI for the rolling scheme iterator

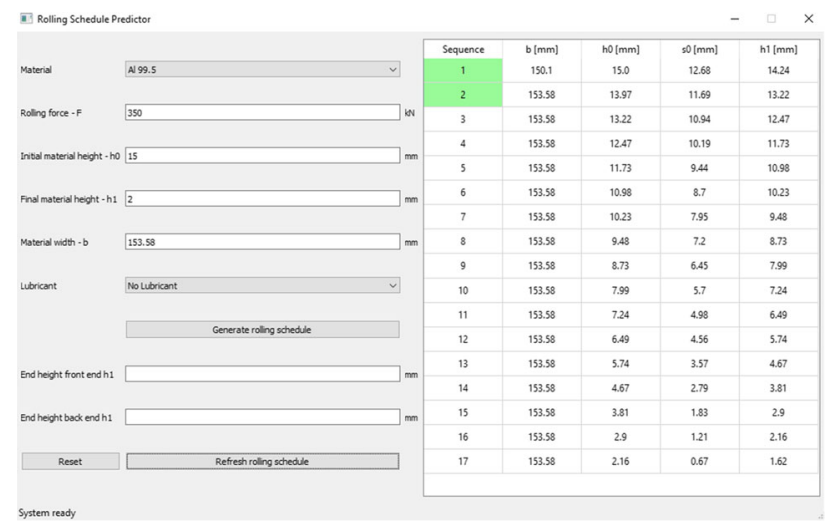

Fig. 40 Changed parameters based on Fig. 38 after the first rolling step: increased width and deviation between measured and predicted $h_{1}$

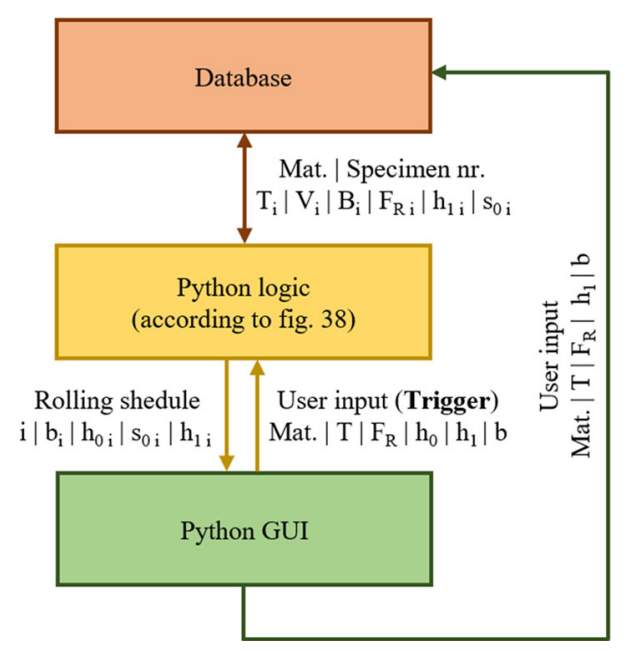

Fig. 41 Overview of the interaction between the database, the corresponding logic (back-end GUI) and visualization (front-end GUI)

To demonstrate the fulfilment of all criteria for a LC usercentered CPPS according to Table 1, Fig. 43 shows the final integration of the system in the layer architecture.

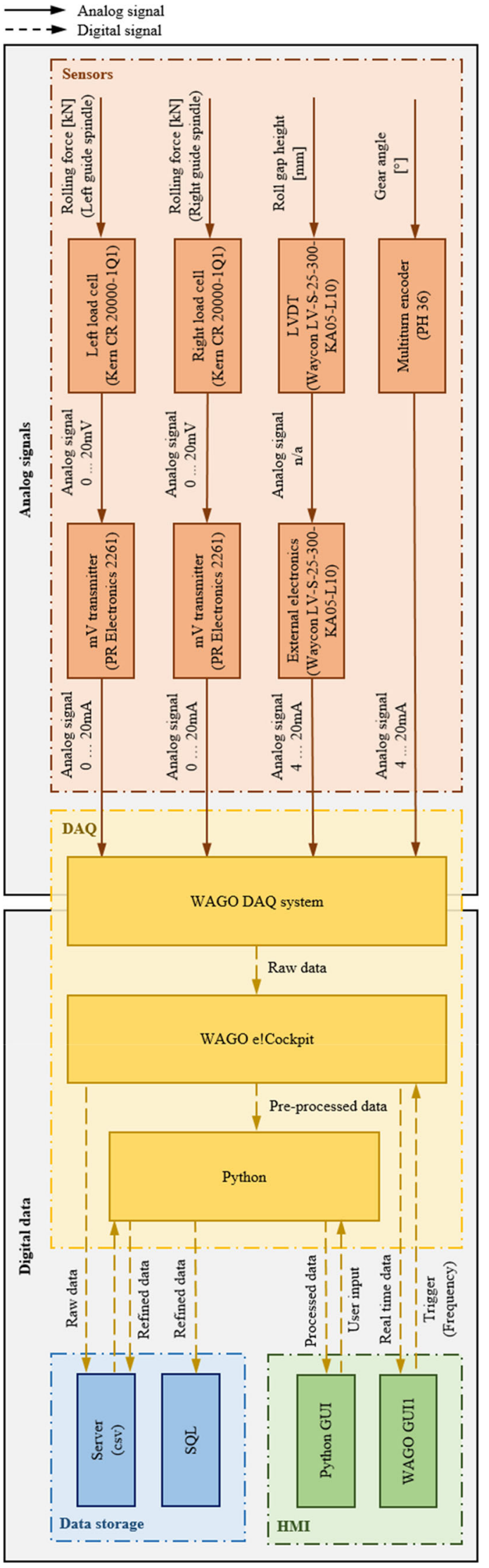

Fig. 42 Resulting data flow for the digitalized rolling mill 


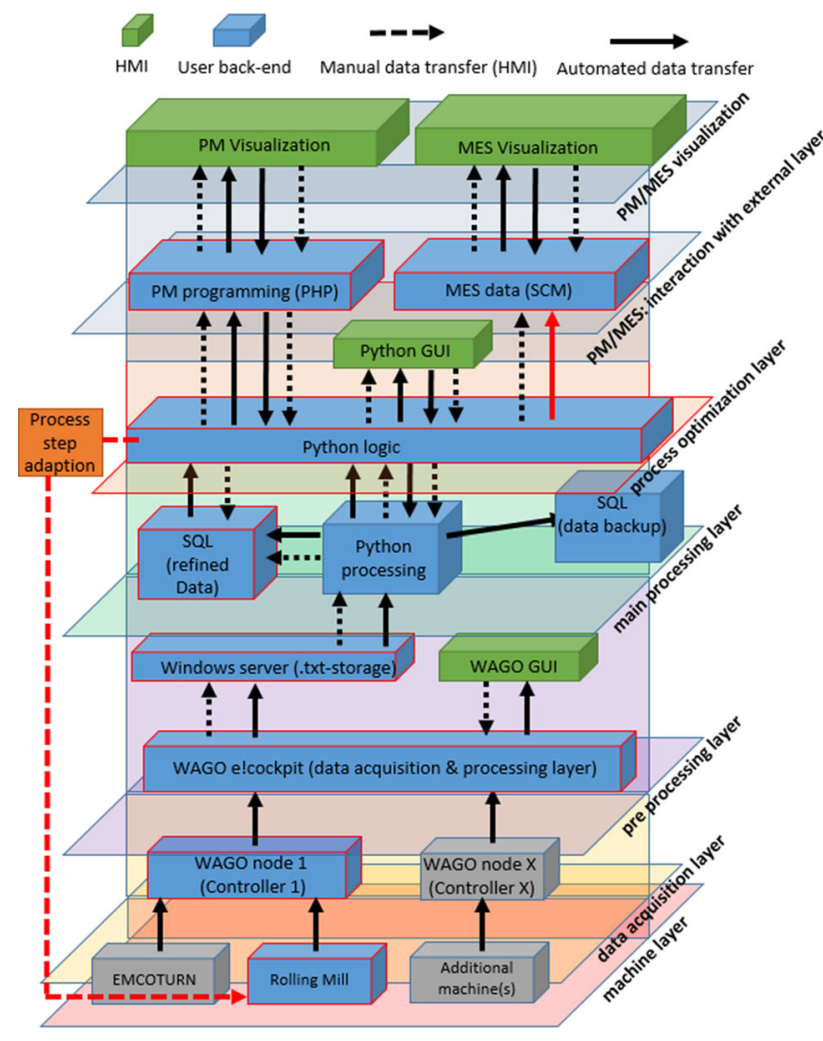

Fig. 43 Resulting layer architecture for the developed CPPS

Depending on the state of the machine (measurement on: $500 \mathrm{~Hz}$; measurement off: $1 \mathrm{~Hz}$ ) a data flow into the MES is automatically enabled or not (Fig. 43, red arrow).

In general, both hypotheses stated initially can be defined as valid. According to the presented architecture, for a resilient and sustainable implementation of the proposed system, further adaptions depending on the existing infrastructure, available skill sets and budget have to be made. One major advantage of this LC approach is the utilization of industry standard software for the Level 2 automation of the resulting CPPS, which is crucial regarding to legal issues in case of a malfunction within the system in the operational industrial context. While the enhancing decision-making logic is provided by a LC open-source alternative within Python, the only direct machine connection is executed by a certified industrial standard software. This mixed-source approach also ensures the resilience of the machine system within the CPPS and additionally prevents unplanned downtimes due to possible malfunctions within the ML algorithm. As the process-material interaction becomes more complex, a simple numerical substitution as demonstrated in this work might also not be efficient anymore. By using Python and its available interfaces to other programs, e.g. Finite Ele- ment Analysis software can additionally be connected to the system if the resulting complexity requires that. Another important advantage is that Python has a relatively low entrance barrier for respective workers (e.g. free/LC online tutorials), ensuring that no highly specialized IT-personnel is required for maintaining such an algorithm. In general, this approach can be used as a fundament for further adaption and optimization depending on the machine system and corresponding process to be transformed in a CPPS. The focus on LC technologies and digitization approaches based on a brownfield environment provides a reasonable method, especially but not restricted to SMEs, to accelerate their shopfloor digitalization and therefore remain competitive in a globalized and digitalized manufacturing environment.

\section{Conclusion and outlook}

This paper describes the successful transformation from a proprietary machine system to a LC user centered CPPS. Although the resulting integrated machine learning algorithm is based on a purely data-driven modeling approach, the respective material has to be and was considered. Without complementary experiments, the number of possible dependencies between input parameters would result in a far more complex system. The usage of a e.g. neural network based algorithms could be an alternative. A huge disadvantage of a more complex logic, however, would be the missing link between real physical effects and resulting prediction. Especially when considering different, more complex materials then the technical pure aluminum used in this case study, an overfitting effect could be the result. In general, a strict separation between material and machine parameters is not possible, as the dependencies and interactions are too complex to distinguish without a significant error or unreasonable computational and modeling efforts.

To extend the demonstrated framework for other material/process combinations, different alloys with different initial conditions will be implemented in the future. Furthermore, with the support of more advanced material characterization experiments (e.g. REM/EBSD), the prediction of grain size and corresponding anisotropy as a function of the thermomechanical treatment will be investigated. In general, the integration of temperature as an additional depended variable results in a far more complex equation system. To solve such a system in an adequate and reproducible way, the integration of finite element analysis connected to the framework within the Python logic will be investigated, whereas the reduction of computational time can be seen as most critical within such simulations. To decrease this parameter, direct coupling of 
Python based input and output files will be included. After successful coupling, the proposed extended algorithm will be able to predict micromechanical material properties as a function of the thermomechanical treatment. This information can be used to send recommendations into the MES-layer (Fig. 43), which can optimize necessary upstream or downstream heat treatment processes based on this information.

Funding Open access funding provided by Montanuniversität Leoben.

Open Access This article is licensed under a Creative Commons Attribution 4.0 International License, which permits use, sharing, adaptation, distribution and reproduction in any medium or format, as long as you give appropriate credit to the original author(s) and the source, provide a link to the Creative Commons licence, and indicate if changes were made. The images or other third party material in this article are included in the article's Creative Commons licence, unless indicated otherwise in a credit line to the material. If material is not included in the article's Creative Commons licence and your intended use is not permitted by statutory regulation or exceeds the permitted use, you will need to obtain permission directly from the copyright holder. To view a copy of this licence, visit http://creativecomm ons.org/licenses/by/4.0/.

\section{References}

Akkaya, B. (2019). Leadership 5.0 in Industry 4.0. In J. Wang \& J. C. Essila (Eds.), Managing Operations Throughout Global Supply Chains (pp. 136-158). IGI Global.

Ball, A., Gelman, L., \& Rao, B. K. N. (Eds.). (2020). Advances in Asset Management and Condition Monitoring. Springer International Publishing.

Buer, S.-V., Strandhagen, J. W., Semini, M., \& Strandhagen, J. O. (2021). The digitalization of manufacturing: Investigating the impact of production environment and company size. Journal of Manufacturing Technology Management, 32(3), 621-645.

Cardin, O. (2019). Classification of cyber-physical production systems applications: Proposition of an analysis framework. Computers in Industry, 104, 11-21.

Denicolai, S., Zucchella, A., \& Magnani, G. (2021). Internationalization, digitalization, and sustainability: Are SMEs ready? A survey on synergies and substituting effects among growth paths. Technological Forecasting and Social Change, 166, 120650.

Dethine, B., Enjolras, M., \& Monticolo, D. (2020). Digitalization and SMEs export management: Impacts on resources and capabilities. Technology Innovation Management Review, 10(4), 18-34.

Dutta, G., Kumar, R., Sindhwani, R., \& Singh, R. K. (2021). Digitalization priorities of quality control processes for SMEs: A conceptual study in perspective of Industry 4.0 adoption. Journal of Intelligent Manufacturing, 32(6), 1679-1698.

Elkins, D. A., Huang, N., \& Alden, J. M. (2004). Agile manufacturing systems in the automotive industry. International Journal of Production Economics, 91(3), 201-214.

Eller, R., Alford, P., Kallmünzer, A., \& Peters, M. (2020). Antecedents, consequences, and challenges of small and medium-sized enterprise digitalization. Journal of Business Research, 112, 119-127.

Enyoghasi, C., \& Badurdeen, F. (2021). Industry 4.0 for sustainable manufacturing: Opportunities at the product, process, and system levels. Resources Conservation and Recycling, 166, 105362.

Gottstein, G. (2004). Physical Foundations of Materials Science. Springer.
Gupta, H., Kumar, A., \& Wasan, P. (2021). Industry 4.0, cleaner production and circular economy: An integrative framework for evaluating ethical and sustainable business performance of manufacturing organizations. Journal of Cleaner Production, 295, 126253.

German Institute for Standardization (2001). Manufacturing processes: Terms and definitions, division. Metallic materials - Tensile testing', DIN EN 10002-1:2001.

Hasegawa, T., \& Kocks, U. (1979). Thermal recovery processes in deformed aluminum. Acta Metallurgica, 27(11), 1705-1716.

Humphreys, F. J., \& Hatherly, M. (2007). Recrystallization and Related Annealing Phenomena. Elsevier.

Kergroach, S. (2020). Giving momentum to SME digitalization. Journal of the International Council for Small Business, 1(1), 28-31.

Lee, W. H., \& Lee, S. R. (1999). Computer simulation of dynamic characteristics of tandem cold rolling process. KSME International Journal, 13(8), 616-624.

Monostori, L., Kádár, B., Bauernhansl, T., Kondoh, S., et al. (2016). Cyber-physical systems in manufacturing. CIRP Annals, 65(2), 621-641.

Müller, J. M., Buliga, O., \& Voigt, K.-I. (2018). Fortune favors the prepared: How SMEs approach business model innovations in Industry 4.0. Technological Forecasting and Social Change, 132, $2-17$.

Ostermann, F. (2014). Anwendungstechnologie Aluminium. Springer Vieweg.

Ralph, B. J., Schwarz, A., \& Stockinger, M. (2020). An implementation approach for an academic learning factory for the metal forming industry with special focus on digital twins and finite element analysis. Procedia Manufacturing, 45, 253-258.

Ralph, B. J., \& Stockinger, M. (2020). 'Digitalization and digital transformation in metal forming: Key technologies challenges and current developments of industry 4.0 applications. XXXIX. Colloquium on Metalforming: Zauchensee, 2020, 13-23.

Ralph, B. J., Hartl, K., Sorger, M., Schwarz-Gsaxner, A., et al. (2021a). Machine learning driven prediction of residual stresses for the shot peening process using a finite element based grey-box model approach. Journal of Manufacturing and Materials Processing, $5(2), 39$.

Ralph, B. J., Sorger, M., Schödinger, B., Schmölzer, H.-J., et al. (2021b). Implementation of a six-layer smart factory architecture with special focus on transdisciplinary engineering education. Sensors, 21(9), 2944.

Ralph, B. J., Woschank, M., Miklautsch, P., Sorger, M., et al. (2021c). MUL 4.0: Systematic digitalization of a value chain from raw material to recycling. Procedia Manufacturing, 2021, 1-8.

Reiman, A., Kaivo-oja, J., Parviainen, E., Takala, E.-P., et al. (2021). Human factors and ergonomics in manufacturing in the industry 4.0 context: A scoping review. Technology in Society, 65, 101572.

Schwarz, A., Ralph, B. J., \& Stockinger, M. (2021). Planning and implementation of a digital shadow for the friction factor quantification of the ECAP process using a grey box modeling approach and finite element analysis. Procedia CIRP, 99, 237-241.

Simon, J. P. (1979). A review of twin and stacking fault energies in Al, $\mathrm{Mg}$ and Be. Journal of Physics F Metal Physics, 9(3), 425-430.

Sorensen, D. G., Brunoe, T. D., \& Nielsen, K. (2019). Brownfield development of platforms for changeable manufacturing. Procedia CIRP, 81, 986-991.

Wang, Q.-L., Sun, J., Liu, Y.-M., Wang, P.-F., et al. (2017). Analysis of symmetrical flatness actuator efficiencies for UCM cold rolling mill by 3D elastic-plastic FEM. The International Journal of Advanced Manufacturing Technology, 92(1-4), 1371-1389.

Wu, X., Goepp, V., \& Siadat, A. (2020). 'Concept and engineering development of cyber physical production systems: A systematic literature review. The International Journal of Advanced Manufacturing Technology, 111(1-2), 243-261. 
Zheng, T., Ardolino, M., Bacchetti, A., \& Perona, M. (2021). The applications of Industry 4.0 technologies in manufacturing context: A systematic literature review. International Journal of Production Research, 59(6), 1922-1954.
Zhong, R. Y., Xu, X., Klotz, E., \& Newman, S. T. (2017). Intelligent manufacturing in the context of industry 4.0: A review. Engineering, 3(5), 616-630.

Publisher's Note Springer Nature remains neutral with regard to jurisdictional claims in published maps and institutional affiliations. 